Rhode Island College

Digital Commons @ RIC

Master's Theses, Dissertations, Graduate

Master's Theses, Dissertations, Graduate Research and Major Papers Overview

Research and Major Papers

$12-1-2020$

\title{
Stress and Coping Methods Utilized by the SRNA
}

Dawn Hughes

Follow this and additional works at: https://digitalcommons.ric.edu/etd

Part of the Nursing Commons

\section{Recommended Citation}

Hughes, Dawn, "Stress and Coping Methods Utilized by the SRNA" (2020). Master's Theses, Dissertations, Graduate Research and Major Papers Overview. 353.

https://digitalcommons.ric.edu/etd/353

This Major Paper is brought to you for free and open access by the Master's Theses, Dissertations, Graduate Research and Major Papers at Digital Commons @ RIC. It has been accepted for inclusion in Master's Theses, Dissertations, Graduate Research and Major Papers Overview by an authorized administrator of Digital Commons @ RIC. For more information, please contact digitalcommons@ric.edu. 


\section{DETERMINING STRESSORS AND COPING METHODS UTILIZED BY STUDENT REGISTERED NURSE ANESTHETISTS}

by

\section{Dawn Hughes}

A Major Paper Submitted in Partial Fulfillment

of the Requirements for the Degree of

Master of Science in Nursing

in

The School of Nursing

Rhode Island College

2020 


\begin{abstract}
Stress is a health issue that plagues many individuals, with a common occurrence in the SRNA. The purpose of this study was to determine stressors and coping methods utilized by the SRNAs enrolled in the combined Rhode Island College (RIC)/Saint Joseph's Hospital School of Nurse Anesthesia (SJHSNA) program. The theory of Stress, Appraisal, and Coping by Lazarus and Folkman (1984) was used to guide this survey design. Following review and approval by Rhode Island College IRB, 17 participants completed a modified version of a self-assessment tool created by Anthony Chipas CRNA, PhD and Dennis McKenna CRNA, MSNA (Chipas \& McKenna, 2011). Elevated stress levels were consistent with similar studies (Chipas et al., 2012), but unlike previous studies, more positive coping skills were reported. Education on stress and positive coping should begin as early as the interview process for future SRNA candidates and continue throughout their career in anesthesia. More research is needed to determine effective coping mechanisms that could be utilized by a large population. A closer look at substance abuse among CRNAs is also needed to establish prevention plans.
\end{abstract}




\section{Acknowledgements}

I want to thank my entire family for their love and support throughout this journey. To my daughter and best friend, Avery, Momma loves you to the moon and back! To my sisters, Lauren and Sammy, thank you for always being my shoulders to cry on and my number one cheerleaders. I want to thank my dad for always having a cold beer waiting for Jessie and me; you sure know your girls! To my anesthesia sisters, Jessie and Beth, I am so grateful our paths aligned because I couldn't have done this without you. Susie you have and will always be my "Wonderwall." To my second momma, Beth Rezendes, thank you for inspiring me and helping me find my way. Thank you to my first reader Dr. Padula for being so patient and understanding throughout this process. To my anesthesia class, we have grown into such a dysfunctional family and I am so thankful for each and every one of you.

Last, but certainly not least, I want to express my sincerest gratitude for my mom. There are no words to truly express my appreciation for you. You have been there through every trial and tribulation of this process without any hesitation. Over the past two and a half years you have been my babysitter, housekeeper, personal assistant, financial advisor, accountant, therapist, and my overall rock. You are the true definition of a saint and all I can say is- Mom, this one is for you. 


\section{Table of Contents}

Background/Statement of the Problem ….......................................................... 1

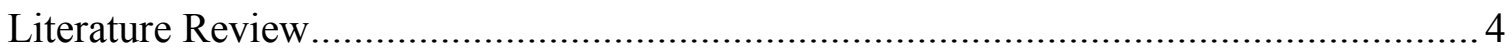

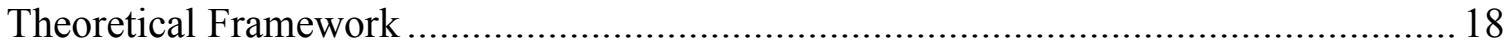

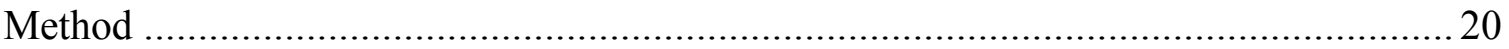

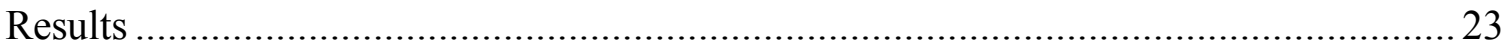

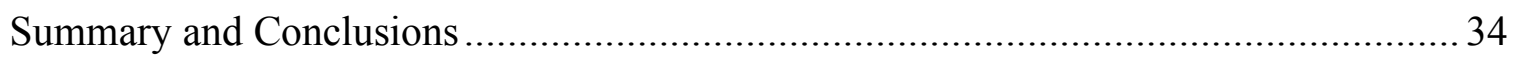

Recommendations and Implications for Advanced Nursing Practice ......................... 38

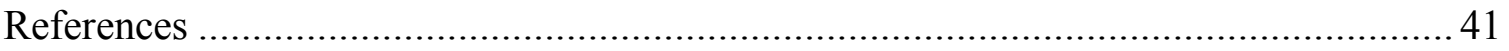

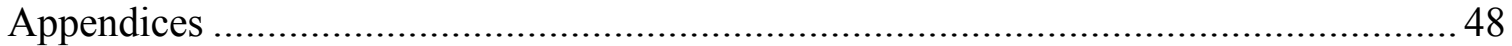


Determining Stressors and Coping Methods Utilized by Student Registered Nurse Anesthetists

\section{Background/Statement of the Problem}

Stress is a common occurrence and affects both the physical and mental health of many individuals (Panda, 2014). Merriam-Webster (2019) defines stress as "a physical, chemical, or emotional factor that causes bodily or mental tension and may be a factor in disease causation." It is the second most common occurring health problem, particularly related to work and is described as a threat to an organism's homeostasis (Panda, 2014). According to Chipas and McKenna (2011), not all stress is bad, and some is needed for motivation and to produce higher performance levels (Griffin et al., 2017). There is a fine line between healthy and unhealthy stress and individuals must recognize their own limitations and seek out appropriate coping methods that work for them.

Cumulative stress can lead to burnout (Aafreen et al., 2018), substance abuse (Bozimowski et al., 2014), poor health conditions, and even suicide (Chipas et al., 2012). Early detection is important to identify and treat overwhelming stress effectively before it has a negative impact (Chipas et al.). It is never too late to get help and treat the consequences of stress, because left untreated, the long-term impact of stress can lead to hypertension, cardiovascular disease, infertility, and even some forms of cancer (Panda, 2014). Yaribeygi et al. (2017) described the impact of stress as involving nearly every system in the human body. Alarming for students, stress has a negative effect on memory and learning (Yaribeygi et al.).

For graduate nursing students, transitioning from the role of the bedside nurse to that of a student learning a new advanced practice role can be extremely stressful. 
Students entering a program may have already begun to establish their lives by starting a family, buying a house, and planning for their future. School can put unforeseen stress on numerous life events if effective coping methods aren't utilized. Uranga (2015) described that student nurse anesthetists (SRNAs) have an immediate increase in stress levels from the very first classroom lecture, most likely resulting from the pressure of having patients' lives placed in their hands. Other stressors include financial burden from loss of income and program costs, extensive coursework, relocation, and limited available time to spend with family and friends (Stone, 2012).

Ways of coping with stress can be both positive and negative. Jahan et al. (2016) summarized positive ways of coping for graduate students in general, including regular exercise, meditation, structured time-outs, and learning new strategies to better combat stress. In a study regarding stress in medical students (Jahan et al.), one-third of students found that better time management, emotional support, family/friend support, and good sleep added to stress reduction. Negative coping methods included overeating, smoking, consuming excessive amounts of alcohol, and increased agitation towards others. In an earlier study by Chipas and McKenna (2011) that specifically pertained to stress and burnout in SRNAs, positive coping methods included exercise, reading, spending time with pets, seeking help and support from others, and connecting with one's spiritual side. Negative coping included sleeping excessive amounts to abusing drugs and alcohol (Chipas \& McKenna).

Finding the right coping method can help students with management of stress. Optimism, positivism, and belief in oneself is a helpful triad that can be used to mitigate stress (Uranga, 2015). It is important to promote wellness in every aspect of the student's 
life, including physical, mental, and social well-being (Griffin et al., 2017). Conner (2015) stressed the importance of social support and increasing the self-efficacy of the student to promote success within the program.

The purpose of this study was to determine stressors and coping methods utilized by the SRNAs enrolled in the combined RIC/SJHSNA program. Next, the review of the literature will be presented. 


\section{Literature Review}

\section{Stress: Definition and Defining Characteristics}

Stress is a common occurrence in many individuals throughout the world and has been studied extensively for years. According to Lazarus and Folkman (1984), stress occurs when an individual perceives an outside stimulus as harmful. It takes into account the characteristics of the person and the severity of the environmental stimulus. Certain stressors such as a tornado, military combat, death of a loved one, etc. would cause similar reactions from individuals; however, day to day stressors can be perceived very differently from person to person. Stress has been characterized as any negative external stimulus that disrupts an organism's internal balance or homeostasis (Stephens \& Wand, 2012) and as an environmental event that distracts a person from operating at an optimal state (Oken et al., 2015).

The main response system to stress within the human body, as well as other mammals, is the hypothalamic-pituitary-adrenal (HPA) axis (Stephens \& Wand, 2012). This system is regulated to respond promptly to stress by increasing stress hormones, glucocorticoids and primary cortisol in humans, and then returning to a normal state just as quickly. A negative-feedback system is used by the HPA axis to limit prolonged activation of stress hormones, because too little or too much exposure to cortisol can be damaging to the body and a person's overall well-being. When an individual is exposed to prolonged and cumulative stress, cortisol levels remain high, putting the individual at risk for neuropsychiatric and metabolic disorders (Stephens \& Wand). 
Stressors can be defined as psychogenic or neurogenic (Anisman \& Merali, 1999). A psychogenic stressor is psychological, and examples include divorce, death of a loved one, work, etc. A neurogenic stressor needs a physical stimulus such as a headache, abdominal pain, surgery, etc. Stress can initially cause depressive and/or anxiety symptoms (Anisman \& Merali); however clearly identifying symptoms of stress for every individual is nearly impossible (Amirkhan et al., 2018). Characteristics that can determine the severity of the stress include degree to which the stressor can be managed or eliminated, predictability of the onset of a stressor, length of exposure to the stressor, and the timing and frequency of the stressor (Anisman \& Merali, 1999).

In a longitudinal study designed by Amirkhan et al. (2018), 440 adults were recruited from a courthouse and an aquarium within a community. Of the 440, 408 (93\%) completed on-site surveys and $161(40 \%)$ completed and returned follow-up surveys one week later. Participants were given a checklist with 35 listed somatic symptoms and another checklist consisting of 35 behavioral symptoms. Somatic symptoms identified by the participants included but were not limited to appetite change, weight change, low sex drive, cold sores, nausea, vomiting, headache, muscle aches, racing heart, and swollen glands. Behavioral symptoms included nervousness, difficulty making decisions, drinking more coffee, losing focus, impatience, cancelling, making more mistakes, and pacing back and forth. The authors found behavioral symptoms were evident almost immediately following a stressor, while somatic symptoms could take hours to days to surface. 


\section{Stress and Impact on Health}

Stress can have both positive and negative effects on the body. Without any type of stress, the ability to respond to future stressors would be lost; therefore, some exposure to stress is useful to promote learning and maintain cognitive function (Oken et al., 2015). Negative sequalae of stress can range from physical, emotional, behavioral, and cognitive symptoms (Panda, 2014), leaving hardly any part of the body untouched.

The "flight-or-fight" response is a well-known theory that was first introduced in the 1920 s by Walter Cannon in an attempt to characterize the response of the sympathetic nervous system (SNS) and endocrine system to stress (Cherry, 2019). The response results in either running from the threatening event (flight) or confronting the stressor (fight).

The SNS is activated by an immediate threat to the individual (Patnaik, 2014). Catecholamines are then released by the adrenal glands, which in turn increases blood pressure, heart rate, and breathing rate. Pupils become dilated, skin becomes flush or pale, muscles become tense, and the mind becomes alert (Cherry, 2019). Following the discontinuation of the threat, whether by running from or resolving it, the body can take 20-60 minutes to return to homeostasis by the overtake of the parasympathetic system.

The long-term effects of chronic stress on the nervous system has been studied for over five decades (Yaribeygi et al., 2017). It has been shown to cause atrophy of the brain and a reduction in brain weight. Increased stress hormones can cause memory disorders and can also interfere with learning. However, in some instances, stress can do 
the opposite and improve memory and learning, the deciding factor being the amount of time exposed to stress (Yaribevgi et al.).

Cardiovascular effects of stress usually begin with an increase in heart rate and blood pressure, increasing oxygen demand, and eventually putting the patient at risk for a myocardial infarction. According to Steptoe and Kivimäki (2013), chronic stress throughout early life and adulthood can put an individual at an increased risk of $40-60 \%$ for developing coronary heart disease (CHD) and atherosclerosis later in life. Stress can also elicit bad behavior such as smoking, which will also have a negative impact on the heart long term.

The gastrointestinal system can be heavily impacted by stress. Stress has been linked to diseases such as irritable bowel syndrome, Crohn's disease, and ulcerative colitis (Yaribevgi et al., 2017). Studies have shown stress can affect gastric acid secretion, GI inflammation, and the absorption process. New research is being done to understand the effect stress has on metabolic syndrome. Metabolic syndrome is defined by having three or more of the following factors: obesity, hypertension, hyperlipidemia, increased triglycerides, or low levels of high-density lipoprotein (HDL). According to Steptoe and Kivimaki (2013), recent studies have confirmed a link to stress and obesity.

\section{Stress and Coping}

Adaptation to stress is individualized and there are many ways to cope using positive mechanisms, as well as negative ones. Coping is defined by Lazarus and Folkman (1980) as "the cognitive and behavioral efforts made to master, tolerate, or reduce external and internal demands and conflicts among them”(p. 223). Lazarus and 
Folkman separate coping into two types: problem-focused and emotion-focused. Problem-focused coping deals with changing the individual's interaction with the environment when a stressful event is presented. Emotion-focused coping deals with changing the individual's perception of the stressor since the person-environment interaction itself cannot be changed (Lazarus \& Folkman).

Baqutayan (2015) studied the evolution of stress and coping mechanisms, and the different theories that describe their relationship. Ways of problem-focused coping include confrontative coping, seeking social support, and plan full problem-solving. Ways to use emotion-focused coping include self-control, seeking social support, distancing, positive appraisal, accepting responsibility, and escape/avoidance. While either of these can be used with a positive outcome, Baqutayan explained that depending on the situation, a negative effect could result. For instance, a student taking on a task full force (problem-solving) that is out of their scope of knowledge could result in negative feelings such as anger and disappointment. On the other hand, if the student used humor to joke about it or discussed their feelings with a friend, a positive outcome would occur (Baqutayan).

In a study by Patnaik (2014), some positive ways of coping with stress included time management, deep breathing, and optimism in order to bring the body back to a steady state. Ways to promote optimism included being social, positive self-talk, and positive emotion to combat stress. On the other hand, negative coping methods included escaping the problem, giving up before the stressor is relieved, and misuse of power to control others. 


\section{Measurement of Stress}

Over the years, several tools have been designed to measure stressful events such as the Social Readjustment Rating Scale (SRRS) (Holmes \& Rahe, 1967) and the Occupational Stress Indicator (Cooper, Sloan \& Williams, 1988); however, they pertain to certain conditions, making them limited to certain groups of people (Taylor, 2015). In 1983, Cohen, Kamarck, and Mermelstein developed a global scale of stress named the Perceived Stress Scale (PSS), which has gained popularity since. Since its creation, three versions have been put into use: a 14-item form (PSS-14), 10-item form (PSS-10), and a 4-item form (PSS-4). Through trial and error, the PSS-10 has gained popularity and is the most widely used version (Taylor). The PSS consists of a self-report measure on a Likert-type scale with responses ranging from 1 (never) to 5 (very often) (Taylor).

Andreou et al. (2011) examined the reliability and validity of the PSS (versions 4, 10, and 14) in Greece. The study took place in hospitals, public services, and universities in four Greek cities between October 2009 and April 2010. Anonymous questionnaires were distributed with a letter explaining the purpose of the study, the researchers contact information, and the fact that all answers would be confidential. Nine hundred and forty-one individuals responded to the survey. The questionnaires consisted of the PSS-14, a 21 item Depression, Anxiety, and Stress scale (DASS-21), and a list of stress-related symptoms. The PSS-14 was also compared to the reliability and validity of the PSS-10 and PSS-4. Consistency and validity were noted between the PSS-14 and the PSS-10, while minimal results were presented for the PSS-4 due to the simplicity of this version and the inconsistent results among this group of participants. Results of the PSS were then compared to the DASS-21 and the stress symptoms checklist. Results of the 
three tests were consistent across the board and with each other. The more symptoms of stress identified, the more severe in the DASS stress subscale the individual fell into, strongly relating to the increase in the PSS score (Andreou).

Another measurement for stress is the combined tool of the Depression Anxiety Stress Scales-21 (DASS-21). Created in 1995 by Lovibond and Lovibond, the DASS-21 is a 21 item self-reporting questionnaire that measures depression (seven items), anxiety (seven items), and stress (seven items) in adults (Lovibond \& Lovibond; as cited by Gomez et al., 2014). Gomez et al. examined the measurement and invariance among men and women using the DASS-21. To do so, 687 participants were recruited from the general community of Victoria and Tasmania, Australia. Four hundred and sixty women and two hundred and twenty-seven men were recruited from shopping centers and sporting and recreational clubs; while other participation was established through newspaper ads, flyers, radio ads, and word of mouth. Questionnaires were distributed and returned back to research assistants or mailed back in pre-paid envelopes. With the exception of three out of twenty-one items differing across sex, there was positive data to support the measurement and invariance among men and women using the DASS-21 and indicate the same scaling properties across genders. Comparable depression scores among men and women were also seen in this study, which is unusual due to the fact that much evidence points to higher levels among women than men (Gomez et al.).

\section{Contributors to Stress in Graduate Students}

Stress can encourage students to strive to do their best and succeed in their studies. However, excessive stress can also lead to health problems as previously 
discussed. Perceived stress varies from individual to individual and can exert positive and negative effects depending on the person. Graduate students are three times more likely to suffer from depression and mental health disorders than the average American (Puri, 2019). For some, graduate school is the expected next step towards becoming an adult, while others pursue post baccalaureate studies to become more knowledgeable in a field they are passionate about (Puri).

In a study by Welle and Graf (2011), college students' stress and coping strategies were identified through a survey method in order to determine effectiveness of lifestyle habits. Exercise, having enough leisure time, strong social support, and greater than eight hours of sleep were listed as effective coping methods utilized. Having the appropriate resources available can alleviate some of the daily academic stress put on the student (Welle \& Graf).

In a qualitative study by Sohail (2013), a questionnaire was distributed to 250 first year medical students of Allama Iqbal Medical College to determine the relationship between stress and academic performance, along with identification of stressors and coping strategies. One hundred twenty were returned and 12 students agreed to a personal interview. Over $70 \%(\mathrm{n}=86)$ of students acknowledged having moderate stress, while over $20 \%(\mathrm{n}=25)$ admitted to suffering from severe stress. Female medical students were identified as having higher stress levels than males. Stressors unanimously identified throughout the participants included lack of leisure time, excessive workload, and competitive nature regarding examinations. Alcohol intake, cigarette smoking, and internet chatting/texting friends were utilized as coping strategies. Overall, however, this study recognized that higher stress levels correlated with poor academic performance. 
Grady et al. (2013) interviewed a mix of 17 graduate and doctorate students were interviewed in a focus group setting and data were collected to identify the social and stress experiences during their studies. Role strain was a common issue that arose throughout the focus groups. Prioritizing was a major hurdle many had to overcome in order to be successful in school and everyday life. Many were not prepared for what graduate school entailed, even though most excelled in their undergraduate studies. Mixed opinions were identified in regard to mentorships with their program. Some voiced it was beneficial, while others felt the mentor's concern leaned more towards the success of the program, rather than the student. Isolation was another common theme that arose during the focus groups. Students felt isolated from friends and family that weren't affiliated with university life. Another unanimous topic was financial strain. Many worried about funding semester to semester and worked multiple jobs to get by. This study identified three areas of improvement for graduate programs: strong mentorship programs focused on the student; encouraging social ties to combat isolation; and institutional financial support if possible, to decrease debt and lessen the financial burden placed on the graduate student (Grady et al.).

\section{Contributors to Stress in SRNAs}

Many studies have been conducted that identify the occurrence of stress and need for social support in SRNAs (Conner, 2015). In regard to nursing students in particular, stress can lead to sleep disturbances, high anxiety, and failure to complete the program. Conner performed a review of the literature and identified the challenges of going from a clinical expert in the field of nursing, to a novice in a new role as a SRNA. High levels of self-efficacy can increase academic performance, as well as improved student 
retention. Four characteristics of self-efficacy include confidence, capability, persistence, and strength in order to overcome the stressors of nurse anesthesia school and promote student retention. The skills and practice of anesthesia occur in a stressful environment and cannot be avoided. Most nurse anesthetist programs require full-time study and do not allow time for employment opportunities, resulting in financial strain. Timeconsuming studies reduce time available for social supports that once relieved stress (Conner, 2015). Conner concluded the importance of strong social support and stress management for the SRNA's mental health and overall school performance.

In a study conducted by Chipas and McKenna (2011), 28,000 invitations via email to a survey were distributed by Wanda Wilson CRNA, PhD, president of the American Association of Nurse Anesthetists (AANA) to CRNAs and SRNAs. Data were collected between February and May of 2008 with responses from $26.9 \%(n=7,537)$. Of the 7,537 responses, $15 \%(\mathrm{n}=1131)$ were from SRNAs. Student stress levels averaged 7.2 on a 10-point Likert scale and 4.7 for the established CRNA. The major stressors identified by the SRNAs were starting school $(75.4 \%, \mathrm{n}=853)$, moving $(43.8 \%, \mathrm{n}=495)$, and quitting a job $(43.8 \%, \mathrm{n}=495)$. Other stressors included death of a loved one $(20.6 \%$, $\mathrm{n}=233)$, personal illness/injury $(12.7 \%, \mathrm{n}=144)$, caretaker for a loved one $(8.8 \%, \mathrm{n}=100)$, and bankruptcy $(9.7 \%, \mathrm{n}=129)$.

A later study from Chipas et al. (2012) followed up with 121 practicing CRNAs that participated as SRNAs in the earlier study and indicated their stress levels decreased to a mean score of 4.6 from 7.2. This descriptive study by Chipas et al. was designed to identify and understand the stress exuded by SRNAs. A study-specific questionnaire was created from a modified survey tool used in a prior study by the senior author. The survey 
was distributed via e-mail to 1,374 associate members of the AANA enrolled in programs throughout the country. The known stressors identified by students included starting school after being out for some time, quitting a job, and a reduction in income. Chipas et al. further identified birth of a child $(5 \%, n=69)$, death of a family member $(13 \%, n=179)$, divorce $(2.5 \%, n=34)$, marriage $(12.2 \%, n=168)$, and personal injuries $(9.4 \%, n=129)$ as forms of stress specific to the SRNA in their study. The mean stress level of the SRNA was 7.2 on a 10-point Likert- scale.

\section{Stress and the COVID-19 Pandemic}

Coronavirus (COVID-19) was first detected in Wuhan, China in December 2019 (Sahu, 2020). Since then, it has spread rapidly around the world and was declared a pandemic by the World Health Organization (WHO) in March 2020. As of August 22, 2020, there were 22,812,491 confirmed cases and 795,132 deaths around the world associated with COVID-19 (WHO, 2020).

Many countries put plans in place to limit and stop the spread of COVID-19 including travel restrictions, social-distancing, business closures, self-isolation, and working from home (Sahu, 2020). Early research suggested that the elderly population was greatly at risk, with minimal effect on the pediatric population. However, it became clear that stopping the spread of the virus among children and young adults was needed to reduce the spread even further (Sahu).

According to Sahu (2020), research exists to support closure of schools and universities in order to break the chain of transmission. In March 2020, over 150 countries closed their schools and universities, affecting over $80 \%$ of students 
nationwide. Universities moved quickly to transition classes to online and canceling workshops, sports events, and other various campus activities (Sahu).

Sahu (2020) outlined the challenges that college students must face during this unforeseen time. Since it is not unusual for a student to move away from home to attend college, students worried about not only their well-being, but also the well-being of their friends and families hundreds and thousands of miles away. Many final exams and graduations were postponed. Not only did the graduates of this academic year face an obstacle with limited employment opportunities, future graduates will continue to face challenges due to the global recession caused by COVID-19 (Sahu).

In a survey design study, Odriozola-González et al. (2020) examined the emotional physiological symptoms of college students and faculty at a Spanish university due to COVID-19. An online survey of 66 multiple choice questions was distributed to the students and workers of the university. The survey utilized two scales: the DASS-21 and the Impact of Event Scale (IES), which is a 4-point Likert type scale that assesses subjective stress associated with a traumatic life event. Two subscales are included in the IES tool: avoidance and intrusion. Questions consisted of demographic data, present and past psychiatric treatment and medications, personal experience during quarantine, personal and social relationships during quarantine, personal concerns for family and friends, and economic concerns during the pandemic. Of the 2,530 participants, higher depression, anxiety, and stress scores were seen in students as opposed to faculty with mean values and standard deviations of $5.52 \pm 4.92$ for depression, $3.34 \pm 3.87$ for anxiety and $6.81 \pm 4.72$ for stress. According to the IES tool, $12.5 \%(\mathrm{n}=317)$ showed severe symptoms, while $75 \%(\mathrm{n}=1,898)$ showed mild to moderate. Although showing lower 
avoidance and intrusion scores compared to undergraduates, Master's level students scored higher on both compared to faculty. Higher physiological impact scores were seen on the IES compared to the DASS-21 anxiety and depression scores. This is most likely due to the fact that the IES addresses event specific questions, such as COVID-19's impact on the individual, as opposed to the non-specific questions about general anxiety and depression asked by the DASS-21 (Odriozola-González et al.).

\section{Coping Methods of SRNAs}

It is very well documented in the literature that SRNAs have a higher than average stress level compared to other graduate students due to the competitive nature of the program and the changes and challenges that accompany it (Chipas et al., 2012). Similar to the general population, SRNAs display both positive and negative coping methods.

The Chipas et al. (2012) study identified exercise was a significant source of stress relief for nurse anesthesia students. The more frequent and consistently the students exercised, the lower their overall stress was. The most beneficial amount of exercise that was linked to lower stress levels in the SRNAs were daily $(\mathrm{n}=59)$ and several times a week ( $\mathrm{n}=372)$, both with a mean stress score of 6.7 out of 10. Many students identified positive activities that limited thinking and allowed their minds to rest such as listening to music, playing with pets, cleaning the house, watching television, and meditating. Others would use humor and positive support from peers to alleviate stress (Chipas et al.). 
On the other hand, negative coping mechanisms included giving up on oneself, gossiping to let unpleasant feelings out, turning to drugs and alcohol, and expressing inappropriate negative feelings. Chipas et al. (2012) reported a significant $47.3 \%$ $(\mathrm{n}=554)$ of SRNAs suffered from depression (stress vs. depression $\mathrm{P}<.05)$. Many students reported help was sought in an attempt to lessen their stress. Approximately $17 \%(\mathrm{n}=183)$ of those surveyed reported taking prescription medication in order to deal with their daily stressors associated with school. An alarming 21.2\% $(n=245)$ reported thoughts of suicide at some point throughout the program. Of the 1,374 students surveyed, $6.3 \%(\mathrm{n}=60)$ reported knowing another individual who committed suicide during their program. Recommendations included recognizing stress early on and implementing stress reduction techniques before harmful symptoms arise. Encouraging physical activity was also mentioned as a way to combat stress.

Unfortunately, with limited time available to concentrate on oneself and overall wellness, negative coping mechanisms can arise. In a cross sectional, retrospective study by Bozimowski et al. (2014), surveys were sent to nurse anesthesia program directors inquiring about known substance misuse among the 2,439 students enrolled over a fiveyear span. Of the 23 program directors that responded to the survey, 14 acknowledged at least one incidence of substance misuse by a student and two programs identified two incidences over the past five years. Clearly nurse anesthesia programs are intense but recognizing warning signs of negative coping and securing resources ahead of time would be beneficial for the overall health and success of the students.

Next, the theoretical framework that guided this study will be explained. 


\section{Theoretical Framework}

The theory of Stress, Appraisal, and Coping by Lazarus and Folkman (1984) was used to guide this study. Originally developed by Lazarus in 1966, many revisions have taken place since, including taking a closer look at positive emotions produced during the stress process (Folkman \& Moskowitz, 2007). This theory focuses on how the person interprets and handles stress, as opposed to other theories such as Selye's theory, which directs the focus to the body's physiological response to stress (McEwen \& Wills, 2019). Stress can be viewed as the relationship between the person and their environment, not a particular external stimulus (Krohne, 2002). Two key components that are outlined within the theory are appraisal and coping (Lazarus \& Folkman, 1984).

Understanding appraisal is important in order to differentiate harmful and harmless situations. It is the immediate emotional reaction to a situation leading to a chain of cognitive activities and complex thoughts in order to react to the initial threat (Lazarus \& Folkman, 1984). Appraisal is divided into three categories: primary; secondary; and reappraisal (McEwen \& Wills, 2019). According to Lazarus and Folkman (1984), primary appraisal can be irrelevant, benign-positive, or stressful. Irrelevant appraisal typically has no effect on the individual. Benign-positive appraisals are associated with positive emotions such as joy and happiness. Stressful appraisals are associated with feelings of threat and challenge. Secondary appraisal deals with the individual's response to the stressor and evaluates if the coping method used is working. Reappraisal is re-evaluating the appraisal once new information has been obtained (Lazarus \& Folkman). Specific patterns of appraisal can lead to different types of stress. 
Harm, threat, and challenge are types of physiological stress that can elicit certain emotions, showing the close relationship between stress and emotions (Krohne, 2002).

In order to tackle the emotions created by the appraised stress, the individual must use the process of coping (McEwen \& Wills, 2019). As with appraisals, coping is further divided into two categories: problem-focused and emotion-focused (McEwen \& Wills). Problem-focused coping deals with changing the person-environment interaction causing the stress, whereas emotion-focused coping is directed at regulating the distress within the individual since the harmful or challenging interaction cannot be altered (Lazarus \& Folkman, 1984).

Successful coping will then lead to adaption by the individual. The three areas of an individual affected by adaption include health, physiological well-being, and social functioning. All of these areas are intertwined and when one is affected, the others will also be affected (McEwen \& Wills, 2019). Positive coping methods in response to stress can thus lead to adaption, allowing the individual to survive and flourish (Lazarus \& Folkman, 1984).

Next, the methods of the study will be discussed. 


\section{Method}

\section{Purpose}

The purpose of this study was to determine stressors and coping methods utilized by the SRNAs enrolled in the combined RIC/SJHSNA program.

\section{Design}

This study utilized a survey design.

\section{Sample and Site}

Students enrolled in the Rhode Island College (RIC)/SJHSNA who had completed NURS 517: Foundational Principles of Nurse Anesthesia were included. Exclusion criteria included students enrolled in the SJHSNA program who had not yet completed NURS 517: Foundational Principles of Nurse Anesthesia.

\section{Procedures}

Institutional Review Board (IRB) approval from RIC was obtained. Students meeting the inclusion criteria were informed of the survey via email and invited to participate via an IRB approved informational letter. Participants were e-mailed a link to an online survey website, Survey Monkey, where the surveys were completed anonymously. No IP addresses were collected. 


\section{Measurement}

The survey utilized a self-assessment tool created by Anthony Chipas CRNA, $\mathrm{PhD}$ and Dennis McKenna CRNA, MSNA while conducting a research study of stress in nurse anesthesia (Chipas \& McKenna, 2011). The survey (Appendix A) is separated into sections that first identified the participants' demographics, followed by stress manifestations including symptoms, recent life changes, and satisfaction with work and home life. Self-assessments of stress levels and coping are also identified. Since the survey was distributed through the AANA and to all its members, the AANA requested the addition of an assessment for chronic illnesses among the participants. Data from this study were consistent with results from prior studies identifying stress levels among nurse anesthesia providers (Chipas \& McKenna), validating its credibility.

Since the survey addressed both CRNAs and SRNAs, the questions were reviewed for those that were more pertinent to SRNAs and their stress experience while in a nurse anesthesia program. Questions regarding employment as a CRNA were omitted, as well as questions about program details, since all participants will be from the same program. Certain demographics were not used to keep participants anonymous since the study sample was small. The self-assessment sections on stress levels and coping did not need modification since this information pertains to both students and CRNAs alike. A section on the impact of COVID was inserted at the end of the survey; these questions were piloted by the author (Appendix B).

\section{Data Analysis}

Results were analyzed using basic descriptive statistics (Ali \& Bhaskar, 2016). 
Next, the results will be presented. 


\section{Results}

The survey was e-mailed to 19 possible participants; 17 participants completed the online survey between June $6^{\text {th }}, 2020$ and June $12^{\text {th }}$ 2020, with a response rate of $89 \%$. Table 1 below illustrates the demographic portion of the survey.

\section{Table 1}

Demographics $(N=17)$

\begin{tabular}{|c|c|c|c|c|c|c|}
\hline \multirow{2}{*}{$\begin{array}{c}1 . \\
\text { Marital } \\
\text { Status }\end{array}$} & $\begin{array}{c}\text { Married/ } \\
\text { Partnership }\end{array}$ & $\begin{array}{l}\text { Married/ } \\
\text { Partnership } \\
\text { with } \\
\text { children or } \\
\text { others at } \\
\text { home }\end{array}$ & Divorced & $\begin{array}{l}\text { Divorced } \\
\text { with } \\
\text { children } \\
\text { or others } \\
\text { at home }\end{array}$ & Single & $\begin{array}{l}\text { Single with } \\
\text { children or } \\
\text { others at home }\end{array}$ \\
\hline & $\begin{array}{c}52.9 \% \\
\mathrm{n}=9\end{array}$ & $\begin{array}{c}23.53 \% \\
\mathrm{n}=4\end{array}$ & $0 \%$ & $0 \%$ & $\begin{array}{c}17.65 \% \\
n=3\end{array}$ & $\begin{array}{c}5.88 \% \\
\mathrm{n}=1\end{array}$ \\
\hline \multirow{2}{*}{\multicolumn{2}{|c|}{$\begin{array}{l}\text { 2. When was your last } \\
\text { vacation? }\end{array}$}} & 0-3 Months & $\begin{array}{c}4-6 \\
\text { Months }\end{array}$ & $\begin{array}{c}7-11 \\
\text { Months }\end{array}$ & $\begin{array}{c}1-2 \\
\text { Years }\end{array}$ & $>2$ Years \\
\hline & & $\begin{array}{c}23.53 \% \\
\mathrm{n}=4\end{array}$ & $\begin{array}{c}23.53 \% \\
\mathrm{n}=4\end{array}$ & $0 \%$ & $\begin{array}{c}35.29 \% \\
\mathrm{n}=6\end{array}$ & $\begin{array}{c}17.65 \% \\
n=3\end{array}$ \\
\hline \multirow{2}{*}{\multicolumn{2}{|c|}{$\begin{array}{l}\text { 3. When was your last } \\
\text { sick day? }\end{array}$}} & 1-3 months & $\begin{array}{c}4-6 \\
\text { months }\end{array}$ & $\begin{array}{c}7-11 \\
\text { months }\end{array}$ & $\begin{array}{c}1-2 \\
\text { years }\end{array}$ & $>2$ years \\
\hline & & $\begin{array}{c}17.65 \% \\
\mathrm{n}=3\end{array}$ & $\begin{array}{c}35.29 \% \\
\mathrm{n}=6\end{array}$ & $\begin{array}{c}5.88 \% \\
\mathrm{n}=1\end{array}$ & $\begin{array}{c}17.65 \% \\
n=3\end{array}$ & $\begin{array}{c}23.53 \% \\
\mathrm{n}=4\end{array}$ \\
\hline \multirow{2}{*}{\multicolumn{2}{|c|}{$\begin{array}{l}\text { 4. On average, how many } \\
\text { sick days do you use per } \\
\text { year? }\end{array}$}} & $0-2$ & $3-5$ & $6-8$ & $9-10$ & $>10$ \\
\hline & & $\begin{array}{c}35.29 \% \\
n=6\end{array}$ & $\begin{array}{c}41.18 \% \\
n=7\end{array}$ & $\begin{array}{c}23.53 \% \\
n=4\end{array}$ & $0 \%$ & $0 \%$ \\
\hline
\end{tabular}

The majority of participants were either married or married with children or others at home. Almost half (47.06\%) had taken a vacation in the last six months, while 
the other half $(52.94 \%)$ had not taken one in over a year. All participants took eight or less sick days per year, with half taking one in the last six months.

Table 2 on the next page addresses participants' stress symptoms and how often they occurred. 
Table 2

Stress Symptoms and Frequency $(\mathrm{N}=17)$

\begin{tabular}{|c|c|c|c|c|}
\hline & Weekly & Monthly & $\begin{array}{c}\text { Intermitten } \\
t\end{array}$ & Not at all \\
\hline Agitation/anxious/irritable & $\begin{array}{c}64.71 \% \\
\mathrm{n}=11\end{array}$ & $\begin{array}{c}35.29 \% \\
\mathrm{n}=6\end{array}$ & $\begin{array}{c}5.88 \% \\
n=1\end{array}$ & $0 \%$ \\
\hline Annoyed by trivial things & $\begin{array}{c}64.71 \% \\
\mathrm{n}=11\end{array}$ & $\begin{array}{c}11.76 \% \\
n=2\end{array}$ & $\begin{array}{c}23.53 \% \\
n=4\end{array}$ & $0 \%$ \\
\hline Avoid interactions with others & $\begin{array}{c}47.06 \% \\
n=8\end{array}$ & $\begin{array}{c}17.65 \% \\
n=3\end{array}$ & $\begin{array}{c}23.53 \% \\
\mathrm{n}=4\end{array}$ & $\begin{array}{c}11.76 \% \\
n=2\end{array}$ \\
\hline Cravings/compulsions & $\begin{array}{c}41.18 \% \\
\mathrm{n}=7\end{array}$ & $\begin{array}{c}11.76 \% \\
\mathrm{n}=2\end{array}$ & $\begin{array}{c}17.65 \% \\
\mathrm{n}=3\end{array}$ & $\begin{array}{c}23.53 \% \\
\mathrm{n}=4\end{array}$ \\
\hline Decreased ability to concentrate & $\begin{array}{c}64.71 \% \\
\mathrm{n}=11\end{array}$ & $\begin{array}{c}5.88 \% \\
\mathrm{n}=1\end{array}$ & $\begin{array}{c}23.53 \% \\
n=4\end{array}$ & $\begin{array}{c}5.88 \% \\
\mathrm{n}=1\end{array}$ \\
\hline $\begin{array}{l}\text { Decreased work accomplishments } \\
\text { even though working hard }\end{array}$ & $\begin{array}{c}47.06 \% \\
n=8\end{array}$ & $\begin{array}{c}17.65 \% \\
\mathrm{n}=3\end{array}$ & $\begin{array}{c}11.76 \% \\
\mathrm{n}=2\end{array}$ & $\begin{array}{c}23.53 \% \\
\mathrm{n}=4\end{array}$ \\
\hline $\begin{array}{c}\begin{array}{c}\text { Digestive problems (including } \\
\text { heart burn/GERD) }\end{array} \\
\end{array}$ & $\begin{array}{c}35.29 \% \\
\mathrm{n}=6\end{array}$ & $\begin{array}{c}11.76 \% \\
\mathrm{n}=2\end{array}$ & $\begin{array}{c}11.76 \% \\
\mathrm{n}=2\end{array}$ & $\begin{array}{c}41.18 \% \\
\mathrm{n}=7\end{array}$ \\
\hline $\begin{array}{c}\text { Frequent back or neck } \\
\text { spasms/pain }\end{array}$ & $\begin{array}{c}52.94 \% \\
\mathrm{n}=9\end{array}$ & $\begin{array}{c}11.76 \% \\
\mathrm{n}=2\end{array}$ & $\begin{array}{c}11.76 \% \\
\mathrm{n}=2\end{array}$ & $\begin{array}{c}23.53 \% \\
\mathrm{n}=4\end{array}$ \\
\hline Headaches & $\begin{array}{c}52.94 \% \\
\mathrm{n}=9\end{array}$ & $\begin{array}{c}17.65 \% \\
\mathrm{n}=3\end{array}$ & $\begin{array}{c}17.65 \% \\
\mathrm{n}=3\end{array}$ & $\begin{array}{c}11.76 \% \\
\mathrm{n}=2\end{array}$ \\
\hline Impatient with others & $\begin{array}{c}52.94 \% \\
n=9\end{array}$ & $\begin{array}{c}29.41 \% \\
\mathrm{n}=5\end{array}$ & $\begin{array}{c}11.76 \% \\
n=2\end{array}$ & $\begin{array}{c}5.88 \% \\
n=1\end{array}$ \\
\hline Mood swings & $\begin{array}{c}29.41 \% \\
\mathrm{n}=5\end{array}$ & $\begin{array}{c}23.53 \% \\
\mathrm{n}=4\end{array}$ & $\begin{array}{c}23.53 \% \\
\mathrm{n}=4\end{array}$ & $\begin{array}{c}23.53 \% \\
\mathrm{n}=4\end{array}$ \\
\hline Nervousness/tremors & $\begin{array}{c}5.88 \% \\
\mathrm{n}=1\end{array}$ & $\begin{array}{c}35.29 \% \\
\mathrm{n}=6\end{array}$ & $\begin{array}{c}35.29 \% \\
\mathrm{n}=6\end{array}$ & $\begin{array}{c}23.53 \% \\
\mathrm{n}=4\end{array}$ \\
\hline Sad/discouraged & $\begin{array}{c}35.29 \% \\
\mathrm{n}=6\end{array}$ & $\begin{array}{c}23.53 \% \\
\mathrm{n}=4\end{array}$ & $\begin{array}{c}23.53 \% \\
\mathrm{n}=4\end{array}$ & $\begin{array}{c}11.76 \% \\
\mathrm{n}=2\end{array}$ \\
\hline $\begin{array}{c}\text { Sleep disturbances/insomnia/ } \\
\text { oversleeping }\end{array}$ & $\begin{array}{c}47.06 \% \\
\mathrm{n}=8\end{array}$ & $\begin{array}{c}23.53 \% \\
\mathrm{n}=4\end{array}$ & $\begin{array}{c}23.53 \% \\
\mathrm{n}=4\end{array}$ & $\begin{array}{c}5.88 \% \\
\mathrm{n}=1\end{array}$ \\
\hline Too busy for things I used to do & $\begin{array}{c}58.82 \% \\
\mathrm{n}=10\end{array}$ & $\begin{array}{c}11.76 \% \\
n=2\end{array}$ & $\begin{array}{c}23.53 \% \\
\mathrm{n}=4\end{array}$ & $\begin{array}{c}5.88 \% \\
\mathrm{n}=1\end{array}$ \\
\hline
\end{tabular}

Responses showed weekly occurrences of the following symptoms in the majority of the participants: agitation/anxious/ irritable (64.71\%); annoyed by trivial things (64.71\%); avoid interactions with others (47.06\%); cravings/compulsions (41.18\%); decreased ability to concentrate (64.71\%); decreased work accomplishments 
even though working hard (47.06\%); impatience with others (52.94\%); and too busy for things they used to enjoy (58.82\%). Mood swings and sadness were seen in one-third of the participants. Physical symptoms included digestive problems (35.29\%), frequent back or neck spasms/pain (52.94\%), headaches (52.94\%), and sleep disturbances $(47.06 \%)$.

Table 3 on the next page outlines significant life events that occurred over the past year. 
Table 3

Significant Life Events that Occurred in the Past Year $(N=16)$

\begin{tabular}{|c|c|}
\hline Salary /benefits decreased & $\begin{array}{l}50 \% \\
n=8\end{array}$ \\
\hline Birth of a child & $\begin{array}{c}6.25 \% \\
n=1\end{array}$ \\
\hline Military deployment -significant other/friend & $\begin{array}{c}6.25 \% \\
\mathrm{n}=1\end{array}$ \\
\hline Military deployment -self & $\begin{array}{c}6.25 \% \\
n=1\end{array}$ \\
\hline Bankruptcy /financial crisis & $\begin{array}{c}12.5 \% \\
n=2\end{array}$ \\
\hline Caring for debilitated /chronically ill loved one & $\begin{array}{l}25 \% \\
n=4\end{array}$ \\
\hline Death of a family member /close friend & $\begin{array}{c}12.5 \% \\
n=2\end{array}$ \\
\hline Marriage /legal union & $\begin{array}{c}12.5 \% \\
\mathrm{n}=2\end{array}$ \\
\hline Moved & $\begin{array}{c}12.5 \% \\
n=2\end{array}$ \\
\hline Pregnancy & $\begin{array}{c}6.25 \% \\
\mathrm{n}=1\end{array}$ \\
\hline Personal illness or injury & $\begin{array}{c}12.5 \% \\
\mathrm{n}=2\end{array}$ \\
\hline Quit a job & $\begin{array}{c}6.25 \% \\
n=1\end{array}$ \\
\hline
\end{tabular}

As seen in Table 3 , in order to pursue a career in anesthesia, $50 \%$ of the participants had accepted a decrease in income and/or benefits. A quarter had also been caring for a chronically ill loved one. Twelve and a half percent of participants had experienced a personal injury/illness, moved, got married, or have gone through a financial crisis. Twelve participants rated their stress level six or greater, with another $35.29 \%(n=6)$ reporting a seven. Eighty-eight percent of respondents attributed $70 \%$ or greater of the stress to school. Approximately $76 \%(n=13)$ did not feel empowered to make changes at school; however, $58.82 \%(n=10)$ did feel empowered to make changes 
in their personal life. Seventy percent $(n=12)$ were either satisfied or extremely satisfied with their choice of career in anesthesia with mixed results regarding satisfaction with life outside of school.

Table 4 on the next page illustrates the participants' ways of coping and how frequently they were used. 
Table 4

Ways and Frequency of Coping Methods Utilized $(N=17)$

\begin{tabular}{|c|c|c|c|c|c|c|}
\hline & $\begin{array}{c}\text { Very } \\
\text { Frequently }\end{array}$ & Frequently & Occasionally & Rarely & $\begin{array}{c}\text { Very } \\
\text { rarely }\end{array}$ & Never \\
\hline Turning to schoolwork & $\begin{array}{c}23.53 \% \\
\mathrm{n}=4\end{array}$ & $\begin{array}{c}52.94 \% \\
\mathrm{n}=9\end{array}$ & $\begin{array}{c}11.76 \% \\
\mathrm{n}=2\end{array}$ & $\begin{array}{c}5.88 \% \\
\mathrm{n}=1\end{array}$ & $\begin{array}{c}5.88 \% \\
\mathrm{n}=1\end{array}$ & $0 \%$ \\
\hline Doing household projects & $\begin{array}{c}11.76 \% \\
n=2\end{array}$ & $\begin{array}{c}17.65 \% \\
n=3\end{array}$ & $\begin{array}{c}29.41 \% \\
n=5\end{array}$ & $\begin{array}{c}23.53 \% \\
n=4\end{array}$ & $\begin{array}{c}11.76 \% \\
n=2\end{array}$ & $\begin{array}{c}5.88 \% \\
n=1\end{array}$ \\
\hline $\begin{array}{l}\text { Doing things to make the } \\
\text { situation better }\end{array}$ & $\begin{array}{c}5.88 \% \\
n=1\end{array}$ & $\begin{array}{c}23.53 \% \\
n=4\end{array}$ & $\begin{array}{c}58.82 \% \\
\mathrm{n}=10\end{array}$ & $\begin{array}{c}11.76 \% \\
\mathrm{n}=2\end{array}$ & $0 \%$ & $0 \%$ \\
\hline $\begin{array}{l}\text { Getting emotional support } \\
\text { from others }\end{array}$ & $\begin{array}{c}5.88 \% \\
n=1\end{array}$ & $\begin{array}{c}35.29 \% \\
n=6\end{array}$ & $\begin{array}{c}41.18 \% \\
n=7\end{array}$ & $\begin{array}{c}11.76 \% \\
n=2\end{array}$ & $0 \%$ & $\begin{array}{c}5.88 \% \\
\mathrm{n}=1\end{array}$ \\
\hline $\begin{array}{l}\text { Using alcohol or other } \\
\text { drugs to make myself } \\
\text { better }\end{array}$ & $0 \%$ & $\begin{array}{c}23.53 \% \\
n=4\end{array}$ & $\begin{array}{c}29.41 \% \\
n=5\end{array}$ & $\begin{array}{c}11.76 \% \\
n=2\end{array}$ & $\begin{array}{c}11.76 \% \\
n=2\end{array}$ & $\begin{array}{c}23.53 \% \\
n=4\end{array}$ \\
\hline $\begin{array}{l}\text { Trying to see things in a } \\
\text { more positive light }\end{array}$ & $\begin{array}{c}11.76 \% \\
n=2\end{array}$ & $\begin{array}{c}35.29 \% \\
\mathrm{n}=6\end{array}$ & $\begin{array}{c}52.94 \% \\
\mathrm{n}=9\end{array}$ & $0 \%$ & $0 \%$ & $0 \%$ \\
\hline Criticizing myself & $\begin{array}{c}5.88 \% \\
\mathrm{n}=1\end{array}$ & $\begin{array}{c}29.41 \% \\
n=5\end{array}$ & $\begin{array}{c}58.82 \% \\
\mathrm{n}=10\end{array}$ & $\begin{array}{c}5.88 \% \\
\mathrm{n}=1\end{array}$ & $0 \%$ & $0 \%$ \\
\hline Making jokes about things & $\begin{array}{c}35.29 \% \\
n=6\end{array}$ & $\begin{array}{c}41.18 \% \\
n=7\end{array}$ & $\begin{array}{c}17.65 \% \\
n=3\end{array}$ & $\begin{array}{c}5.88 \% \\
n=1\end{array}$ & $0 \%$ & $0 \%$ \\
\hline $\begin{array}{l}\text { Doing things to think } \\
\text { less... movies, tv, etc }\end{array}$ & $\begin{array}{c}11.76 \% \\
n=2\end{array}$ & $\begin{array}{c}52.94 \% \\
n=9\end{array}$ & $\begin{array}{c}23.53 \% \\
n=4\end{array}$ & $\begin{array}{c}5.88 \% \\
\mathrm{n}=1\end{array}$ & $0 \%$ & $\begin{array}{c}5.88 \% \\
\mathrm{n}=1\end{array}$ \\
\hline $\begin{array}{l}\text { Going out with family/ } \\
\text { friends }\end{array}$ & $\begin{array}{c}5.88 \% \\
n=1\end{array}$ & $\begin{array}{c}11.76 \% \\
n=2\end{array}$ & $\begin{array}{c}41.18 \% \\
\mathrm{n}=7\end{array}$ & $\begin{array}{c}29.41 \% \\
\mathrm{n}=5\end{array}$ & $\begin{array}{c}17.65 \% \\
n=3\end{array}$ & $0 \%$ \\
\hline Meditating & $\begin{array}{c}5.88 \% \\
\mathrm{n}=1\end{array}$ & $\begin{array}{c}11.76 \% \\
\mathrm{n}=2\end{array}$ & $\begin{array}{c}29.41 \% \\
\mathrm{n}=5\end{array}$ & $0 \%$ & $\begin{array}{c}5.88 \% \\
\mathrm{n}=1\end{array}$ & $\begin{array}{c}47.06 \% \\
\mathrm{n}=8\end{array}$ \\
\hline Exercising & $\begin{array}{c}17.65 \% \\
\mathrm{n}=3\end{array}$ & $\begin{array}{c}35.29 \% \\
\mathrm{n}=6\end{array}$ & $\begin{array}{c}11.76 \% \\
n=2\end{array}$ & $\begin{array}{c}5.88 \% \\
\mathrm{n}=1\end{array}$ & $\begin{array}{c}11.76 \% \\
\mathrm{n}=2\end{array}$ & $\begin{array}{c}17.65 \% \\
\mathrm{n}=3\end{array}$ \\
\hline Listening to music & $\begin{array}{c}23.53 \% \\
n=4\end{array}$ & $\begin{array}{c}29.41 \% \\
n=5\end{array}$ & $\begin{array}{c}35.29 \% \\
\mathrm{n}=6\end{array}$ & $\begin{array}{c}5.88 \% \\
\mathrm{n}=1\end{array}$ & $\begin{array}{c}5.88 \% \\
\mathrm{n}=1\end{array}$ & $0 \%$ \\
\hline $\begin{array}{l}\text { Playing with my favorite } \\
\text { pet }\end{array}$ & $\begin{array}{c}29.41 \% \\
n=5\end{array}$ & $\begin{array}{c}11.76 \% \\
n=2\end{array}$ & $\begin{array}{c}23.53 \% \\
n=4\end{array}$ & $\begin{array}{c}11.76 \% \\
n=2\end{array}$ & $0 \%$ & $\begin{array}{c}23.53 \% \\
\mathrm{n}=4\end{array}$ \\
\hline Reading & $\begin{array}{c}5.88 \% \\
\mathrm{n}=1\end{array}$ & $\begin{array}{c}11.76 \% \\
\mathrm{n}=2\end{array}$ & $\begin{array}{c}11.76 \% \\
\mathrm{n}=2\end{array}$ & $\begin{array}{c}23.53 \% \\
\mathrm{n}=4\end{array}$ & $\begin{array}{c}17.65 \% \\
n=3\end{array}$ & $\begin{array}{c}29.41 \% \\
\mathrm{n}=5\end{array}$ \\
\hline Having sex & $\begin{array}{c}5.88 \% \\
n=1\end{array}$ & $\begin{array}{c}17.65 \% \\
n=3\end{array}$ & $\begin{array}{c}29.41 \% \\
n=5\end{array}$ & $\begin{array}{c}17.65 \% \\
n=3\end{array}$ & $\begin{array}{c}23.53 \% \\
n=4\end{array}$ & $\begin{array}{c}5.88 \% \\
\mathrm{n}=1\end{array}$ \\
\hline Sleeping & $0 \%$ & $\begin{array}{c}47.06 \% \\
n=8\end{array}$ & $\begin{array}{c}29.41 \% \\
\mathrm{n}=5\end{array}$ & $\begin{array}{c}17.65 \% \\
\mathrm{n}=3\end{array}$ & $\begin{array}{c}5.88 \% \\
\mathrm{n}=1\end{array}$ & $0 \%$ \\
\hline
\end{tabular}

Turning to schoolwork as well as doing things to think less were frequently used ways of coping in 52.94\% $(n=9)$ of participants. Sleeping was used in $47.06 \%(n=8)$. When asked how frequently the participant exercised, $17.65 \%(n=3)$ said daily, $35.29 \%$ $(n=6)$ said several times per week, while $29.41 \%(n=5)$ stated infrequently. When asked 
about whether he/she had a current personal physician, $76.47 \%(\mathrm{n}=13)$ said "yes," with $35.29 \%(n=6)$ having seen the doctor in the last 3 months. Approximately $53 \%(n=9)$ had seen a dentist within the past 11 months, while $47.06 \%(n=8)$ admitted it has been over a year.

Table 5 below addresses chronic illnesses that the participants suffered from.

Table 5

Chronic Illnesses Suffering From $(N=12)$

\begin{tabular}{|c|c|}
\hline Chronic pain (including back and joint) & $\begin{array}{l}25 \% \\
n=3\end{array}$ \\
\hline Depression & $\begin{array}{c}41.67 \% \\
n=5\end{array}$ \\
\hline GERD (digestive disorders) & $\begin{array}{c}16.67 \% \\
n=2\end{array}$ \\
\hline Hypertension & $\begin{array}{c}8.33 \% \\
\mathrm{n}=1\end{array}$ \\
\hline Latex allergy & $\begin{array}{c}8.33 \% \\
\mathrm{n}=1\end{array}$ \\
\hline Obesity (BMI>25) & $\begin{array}{l}25 \% \\
\mathrm{n}=3\end{array}$ \\
\hline Panic Disorders & $\begin{array}{c}8.33 \% \\
\mathrm{n}=1\end{array}$ \\
\hline Stroke & $\begin{array}{c}8.33 \% \\
n=1\end{array}$ \\
\hline Other (please specify) & $\begin{array}{c}16.67 \% \\
n=2\end{array}$ \\
\hline
\end{tabular}

Among the participants surveyed, depression was identified by $41.17 \%(n=5)$.

Chronic pain and obesity $(\mathrm{BMI}>25)$ were acknowledged by $25 \%(\mathrm{n}=4)$ of participants. When asked to specify other chronic illnesses in the write-in section, one participant responded "anxiety," while another replied "headaches/migraines." Approximately 48\% 
$(n=8)$ of participants reported feeling down, depressed, and/or hopeless within the past month and $58.82 \%(\mathrm{n}=10)$ experienced little interest or pleasure in doing things. While no participant reported thinking of suicide, $25.53 \%(n=4)$ of participants knew a CRNA/SRNA that had committed suicide in the last two years. Five (29.41\%) had sought professional help for stress in the past, yet only $17.65 \%(n=3)$ were being treated for stress at the time of the survey. Three (17.65\%) had a family history of ETOH/chemical dependence. When asked if the participant used prescription drugs now or in the past, $17.65 \%(\mathrm{n}=3)$ replied "yes"; write-in answers included benzodiazepine and antidepressants.

Table 6 below outlines classes of medication that were being used by participants to manage stress and to sleep.

Table 6

Classes of Medications Used to Manage Stress and/or Sleep $(N=11)$

\begin{tabular}{|l|c|}
\hline Alcohol & $\begin{array}{c}63.64 \% \\
\mathrm{n}=7\end{array}$ \\
\hline Antidepressants & $\begin{array}{c}18.18 \% \\
\mathrm{n}=2\end{array}$ \\
\hline Benzodiazepines & $\begin{array}{c}36.36 \% \\
\mathrm{n}=4\end{array}$ \\
\hline \multirow{2}{*}{ Beta Blockers } & $\begin{array}{c}9.09 \% \\
\mathrm{n}=1\end{array}$ \\
\hline \multirow{2}{*}{ Over the counter sleep aids } & $\begin{array}{c}45.45 \% \\
\mathrm{n}=5\end{array}$ \\
\hline Prescription sleep aids & $\begin{array}{c}9.09 \% \\
\mathrm{n}=1\end{array}$ \\
\hline SSRIs & $\begin{array}{c}9.09 \% \\
\mathrm{n}=1\end{array}$ \\
\hline
\end{tabular}


Of the 11 responses, the classes of medications most frequently used were alcohol $63.64 \%(n=7)$, over the counter sleep aids $45.45 \%(n=5)$, benzodiazepines $36.36(n=4)$, and antidepressants $18.18 \%(\mathrm{n}=2)$.

Table 7 on the next page summarizes contributors to stress that participants faced during COVID-19 pandemic. 
Table 7

Contributors to Added Stress During COVID-19 (N=17)

\begin{tabular}{|l|c|}
\hline Financial concerns & $\begin{array}{c}29.41 \% \\
\mathrm{n}=5\end{array}$ \\
\hline Health of self & $\begin{array}{c}23.53 \% \\
\mathrm{n}=4\end{array}$ \\
\hline Health of a loved one & $\begin{array}{c}35.29 \% \\
\mathrm{n}=6\end{array}$ \\
\hline Deferment of graduation & $\begin{array}{c}41.18 \% \\
\mathrm{n}=7\end{array}$ \\
\hline Other (please specify) & $\begin{array}{c}47.06 \% \\
\mathrm{n}=8\end{array}$ \\
\hline
\end{tabular}

Four $(23.53 \%)$ participants reported a stress level of eight at the time of the pandemic and $23.53 \%(n=4)$ reported a level ten (extreme stress), with a mean score of 7.2. Neutral satisfaction levels related to how the program handled COVID were reported by seven $(41.18 \%)$ and $35.29 \%(n=6)$ were dissatisfied. Write in's for Table 7 included lack of communication from program, deployment, lack of study time with children at home, poor online transitioning, and achieving desirable grades.

Next, summary and conclusions will be presented. 


\section{Summary and Conclusions}

Normal day to day stressors can evoke different responses from different individuals and essentially leave no part of the body unaffected. Not all stress is bad; some occurrences are needed to expose and teach an individual to prepare for future stressful events (Oken et al., 2015). Learning how to cope with stress is important, whether it be in positive or negative ways (Jahan et al., 2016). Some positive coping mechanisms include staying optimistic, performing deep breaking exercises, and being aware of time management, while negative coping includes giving up before the stress is relieved and escaping the stressor all together (Patnaik, 2014).

If left untreated, chronic stress can lead to heart problems, infertility, and even some types of cancer (Panda, 2014). Stress can also be linked to cognitive and GI symptoms (Yaribeygi et al., 2017). Since stress is the second most common health problem (Panda, 2014), several tools have been designed over the years to measure it, some gaining in popularity more than others. The 10 item PSS is the most widely used version of its kind (Taylor, 2015) and often current research uses the DASS-21 for its range of questions covering anxiety, depression, and stress (Gomez et al., 2014).

Although stress varies from person to person, whether it be job, home life, or unforeseen events, graduate students were three times more likely to develop depression than the average American. Specific to nurse anesthesia programs, the majority require full-time attendance, necessitating that the SRNA to reduce work and thus income and replace them with time consuming studies (Stone, 2012). It has been documented that 
nurse anesthesia students have elevated stress levels and the need for social support is high (Conner, 2015).

With the detection of COVID-19 and safety parameters put in place by many countries, school closures were seen almost immediately. The impact that the pandemic had on people is important to understand, especially in individuals with already high stress levels, such as students. More research is needed to fully grasp the impact the pandemic has had on so many populations including the SRNA.

The purpose of this study was to determine stressors and coping methods utilized by the SRNAs enrolled in the combined RIC/SJHSNA program. The theory of Stress, Appraisal, and Coping by Lazarus and Folkman (1984) was the theoretical framework that guided this study. Focusing on how a person interprets and handles stress, two key components of this theory are appraisal and coping (Lazarus \& Folkman). Appraisal is the initial emotional reaction to the situation or threat to the individual and coping is how the individual deals with the situation. This study attempted to identify types of stressors SRNAs in the SJHSNA program face and coping methods they use.

After IRB approval was granted, a recruitment e-mail was sent out to potential participants. A modified version of a self-assessment tool created by Chipas and McKenna (2011) was utilized. The modified survey included sections on demographics, stress symptoms and frequency, coping methods, and frequency. A small pilot section on COVID-19 was added by this author. Seventeen SRNAs completed the online survey after reviewing the IRB approved consent document, both of which were administered anonymously through Survey Monkey. 
Similar to prior research (Chipas et al. 2012), results show that SRNAs tended to have a high level of stress while enrolled in a nurse anesthesia school. Of the seventeen participants, twelve $(70.6 \%)$ reported above average stress on a daily basis, with school being the cause of that stress over $88 \%$ of the time. Symptoms of stress tended to present as negative sequelae among the students. Common physical symptoms were back/neck pains, sleeping disturbances, headaches, and digestive problems; emotional symptoms seen in the majority of students included agitation \& anxiety $64.71 \%(n=11)$, impatience 52.94\% $(n=9)$, sadness 35.29\% $(n=6)$, and mood swings $29.41 \%(n=5)$. Major life events had occurred across the participants, adding to the stress..

Mostly positive ways of coping methods were reported by participants, although due to limitations in the study method, it was not assessed whether the approach used actually worked to relieve the stressor or was just attempted. Positive coping methods included turning to schoolwork, sleeping, and doing activities that didn't require much thinking. Although no thoughts of suicide were reported, feelings of sadness and hopelessness were alarmingly identified in roughly half the participants. Alcohol was most commonly used to combat stress, while benzodiazepines, antidepressants, and over the counter sleep aids were reported.

While the COVID-19 pandemic caused a lot of unknowns for the world, the SJHSNA students faced their own set of unknowns. Concerns included finances, health of oneself/loved ones, and if graduation would be postponed.

A small sample size was one limitation of this study. Original plans were to measure stress and coping in St. Joseph Hospital School of Nurse Anesthesia students 
who had already begun clinical; however, the unforeseen pandemic caused the author to modify the inclusion criteria in order to achieve a larger sample size. The COVID-19 questions were piloted by the author and not tested for reliability.

Next, the recommendations and implications for advanced nursing practice will be discussed. 


\section{Recommendations and Implications for Advanced Nursing Practice}

Anesthesia is a high stress profession, so it is not surprising that the stress begins in school. Although some stress is good for motivation and an increase in performance levels (Griffin et al., 2017), Tunajek (2006) questioned how much stress is actually motivational and how much is counterproductive to learning. Financial and lifestyle changes occur frequently in the SRNA transitioning from full-time nurse to full-time student. It would be helpful to ensure that potential students are informed of these potential changes so that an educated decision can be made before accepting enrollment in a CRNA program.

Stress is the second most common occurring health problem (Panda, 2014). Management of stress and education on positive coping methods should begin as early as possible since stress in the nurse anesthesia profession is high, with the highest being in the SRNA (Chipas et al., 2012). Assessing students' mental and emotional health is just as important as frequent assessments of academic performance. Maintaining a close relationship with each student would be helpful in recognizing warning signs of negative coping early and assisting the student to be comfortable enough to come forward when in distress. It would also be beneficial to incorporate a mental health questionnaire to every end of semester meeting between the student and administrator. Resources should be made available and encouraged during what many students consider a high stress time in their life as well as during the stress of transitioning into practice.

Communication and an open-door policy should be established not only between faculty and students in the educational setting, but also between employers and 
employees, especially during transition into practice. Stone (2012) identified that the biggest stressor in the senior SRNA is being able to competently perform as a new graduate CRNA. Since coping mechanisms are learned over time, negative coping may prevail in individuals lacking needed education and support related to using positive coping strategies. This is another reason to start education on stress and coping in the student early in their schooling so it can be carried throughout school and into their transition as a CRNA.

An alarmingly common negative coping mechanism among anesthesia providers is substance use (Wright et al., 2012). The number one occupational factor leading to substance use in anesthesia providers is stress, with frequent access to medication coming in second (Wright et al.). Early detection of such negative coping mechanisms is vital to patient safety and the safety of the anesthesia provider. Of course, early education for students and new graduates on consequences of negative coping skills and substance use is one of the most important factors shown to reduce incidences in providers; however research has shown many inconsistencies between program to program on this topic (Wright et al.). That being said, it is vital to address stress and substance abuse early on during the orientation period as a CRNA. Since it is such a high stress job, being aware of the warning signs and knowing about resources available may help an individual or even a colleague.

Clear and accessible resources should be made available to students as well as CRNAs. Policies should also be established to ensure immediate recognition, treatment, and recovery. Substance use can be a touchy subject, but it should be taken seriously and the only way to do that is making it a familiar topic in the workplace. Anesthesia 
providers should be educated on warning signs of potential abuse in themselves and others. Policies should be put in place that makes the individual comfortable enough to come forward and accept help, knowing their job is not in jeopardy as long as they follow an individualized treatment plan. Individual peer support and support groups should be readily available.

Even though stress in the SRNA is well documented (Chipas et al., 2012), there does not seem to be much follow-up and/or resolution to the problem. Further research is needed to identify if coping mechanisms used by students are helpful or harmful to the individual and if negative coping was identified. Proactive steps should be taken early on to incorporate more positive coping into everyday life before stress becomes unbearable to the individual. Chipas et al. (2012) identified concern that the high stress in SRNAs is not fully appreciated and recommended consistent education on stress and coping before it leads to emotional disorders. Since stress can be considered subjective and varies from individual to individual, Stone (2012) suggested additional research to identify effective approaches to combat stress that will be beneficial for a large number of the population.

Further research is also needed in regard to CRNA substance abuse. According to Wright et al. (2012), nurse anesthetists are most likely grouped into substance abuse among nursing professions and not seen as equal offenders in the anesthesia profession. As nurse anesthetists have the same access to opiates, propofol, ketamine, benzodiazepines, and similar habit-forming medications as anesthesiologists (Wright), they are at equal risk as their anesthesia counterparts in developing an addiction. Additional studies should be conducted that look at substance use in both anesthesiologists and nurse anesthetists to get a more accurate picture of who it affects. 


\section{References}

Aafreen, M., Priya, V., \& Gayathri, R. (2018). Effect of stress on academic performance of students in different streams. Drug Invention Today, 10(9), 1776-1780.

Retrieved from

http://web.b.ebscohost.com.ric.idm.oclc.org/ehost/pdfviewer/pdfviewer?vid=8\&si $\mathrm{d}=9877183 \mathrm{a}-\mathrm{c} 36 \mathrm{c}-48 \mathrm{a} 8-\mathrm{a} 467-9 \mathrm{~d} 21 \mathrm{e} 274 \mathrm{f} 7 \mathrm{e} 1 \% 40 \mathrm{pdc}-\mathrm{v}-\mathrm{sessmgr05}$

Ali, Z., \& Bhaskar, S. B. (2016). Basic statistical tools in research and data analysis. Indian Journal of Anaesthesia, 60(9), 662-669. https://doi.org/10.4103/0019-5049.190623

Amirkhan, J. H., Landa, I., \& Huff, S. (2018). Seeking signs of stress overload: Symptoms and behaviors. International Journal of Stress Management, 25(3), 301-311. https://doi.org/10.1037/str0000066

Andreou, E., Alexopoulos, E. C., Lionis, C., Varvogli, L., Gnardellis, C., Chrousos, G. P., \& Darviri, C. (2011). Perceived Stress Scale: reliability and validity study in Greece. International Journal of Environmental Research and Public Health, 8(8), 3287-3298. https://doi.org/10.3390/ijerph8083287

Anisman, H., \& Merali, Z. (1999). Understanding stress: Characteristics and caveats. Alcohol Research \& Health, 23(4), 241-249.

Baqutayan, S. (2015). Stress and coping mechanisms: a historical overview. Retrieved from https://www.mcser.org/journal/index.php/mjss/article/view/5927 
Bozimowski, G., Groh, C., Rouen, P., \& Dosch, M. (2014, August). The prevalence and patterns of substance abuse among nurse anesthesia students. American Association of Nurse Anesthetists Journal, 82(4), 277-283. Retrieved from https://pdfs.semanticscholar.org/01dd/17cb47eb44866f728d4c057c89fb893b8da4. pdf

Cherry, K. (2019, August 21). How the fight or flight response works. Retrieved from https://www.stress.org/how-the-fight-or-flight-response-works

Chipas, A., Cordrey, D., Floyd, D., Grubbs, L., Miller, S., \& Tyre, B. (2012, August). Stress: Perceptions, manifestations, and coping mechanisms of student registered nurse anesthetists. American Association of Nurse Anesthetists Journal, 80(4), 4955. Retrieved from https://pdfs.semanticscholar.org/28ab/95c2955219073a5cc9ae6913156b83334c0f. pdf

Chipas, A., \& McKenna, D. (2011, April). Stress and burnout in nurse anesthesia. American Association of Nurse Anesthetists Journal, 79(2), 122-128. Retrieved from http://web.a.ebscohost.com.ric.idm.oclc.org/ehost/pdfviewer/pdfviewer?vid=7\&si $\mathrm{d}=57 \mathrm{afdb} 89-5426-437 \mathrm{e}-\mathrm{ad} 46-\mathrm{b} 66 \mathrm{c} 4 \mathrm{df4}$ c94f\%40sessionmgr4007

Cohen, S., Kamarck, T., \& Mermelstein, R. (1983). A global measure of perceived stress. Journal of Health and Social Behavior, 24(4), 385-396. 
Conner, M. (2015, April). Self-efficacy, stress, and social support in retention of student registered nurse anesthetists. American Association of Nurse Anesthetists Journal, 83(2), 133-138. Retrieved from https://www.aana.com/docs/default-source/aanajournal-web-documents-1/self-efficacy-stress-0415-pp133138.pdf?sfvrsn=2bcd48b1_6

Cooper, C. L., Sloan, S. L., \& Williams, S. L. (1988). Occupational stress indicator management guide. Windsor: Nfer-Nelson.

Folkman, S., \& Moskowitz, J. T. (2007). Positive affect and meaning-focused coping during significant psychological stress. In M. Hewstone, H. A. W. Schut, J. B. F. De Wit, K. Van Den Bos, \& M. S. Stroebe (Eds.), The scope of social psychology: theory and applications (p. 193-208). Psychology Press.

Furman, M., Joseph, N., \& Miller-Perrin, C. (2018). Associations between coping strategies, perceived stress, and health indicators. Psi Chi Journal of Psychological Research,23(1), 61-72. doi:10.24839/2325-7342.jn23.1.61

Gomez, R., Summers, M., Summers, A., Wolf, A., \& Summers, J. (2014). Depression Anxiety Stress Scales-21: measurement and structural invariance across ratings of men and women. Assessment, 21(4), 418-426. Retrieved from https://doi.org/10.1177/1073191113514106

Grady, R. K., Touche, R. L., Oslawski-Lopez, J., Powers, A., \& Simacek, K. (2013). Betwixt and between. Teaching Sociology, 42(1), 5-16. doi:10.1177/0092055x13502182 
Griffin, A., Yancey, V., \& Dudley, M. (2017, October). Wellness and thriving in a student registered nurse anesthetist population. American Association of Nurse Anesthetists Journal, 85(5), 325-330. Retrieved from http://web.a.ebscohost.com.ric.idm.oclc.org/ehost/pdfviewer/pdfviewer?vid=4\&si $d=d 7 c 4026 a-4546-4283-8$ e7d-6baacc6be7df\%40sdc-v-sessmgr04

Holmes, T. H., \& Rahe, R. H. (1967). The social readjustment rating scale. Journal of Psychosomatic Research, 11(2), 213-218. doi:10.1016/0022-3999(67)90010-4

Jahan, F., Siddiqui, M. A., Mitwally, M., Al Zubidi, N., \& Al Zubidi, H. (2016). Perception of Stress, Anxiety, Depression and Coping Strategies among Medical Students at Oman Medical College. World Family Medicine Journal/Middle East Journal of Family Medicine, 14(7), 16-23. doi:10.5742/mewfm.2016.92856

Krohne, H. (2002). Stress and coping theories. Retrieved from http://userpage.fuberlin.de/ schuez/folien/Krohne_Stress.pdf

Folkman, S., \& Lazarus, R. S. (1980). An analysis of coping in a middle-aged community sample. Journal of Health and Social Behavior, 21, 219-239.

Lazarus, R. S., \& Folkman, S. (1984). Stress, appraisal, and coping. New York, NY: Springer Pub.

McEwen, M., \& Wills, E. M. (2019). Theoretical basis for nursing. Philadelphia, PA: Wolters Kluwer. 
Merriam-Webster. (2019). Stress. Retrieved from https://www.merriamwebster.com/dictionary/stress

Odriozola-González, P., Planchuelo-Gómez, Á., Irurtia, M. J., \& de Luis-García, R. (2020). Psychological effects of the COVID-19 outbreak and lockdown among students and workers of a Spanish university. Psychiatry Research, 290, 113108. https://doi.org/10.1016/j.psychres.2020.113108

Oken, B. S., Chamine, I., \& Wakeland, W. (2015). A systems approach to stress, stressors and resilience in humans. Behavioural Brain Research, 282, 144-154. https://doi.org/10.1016/j.bbr.2014.12.047

Panda, S. (2014). Stress and health: Symptoms and techniques of psychotherapeutic management. Indian Journal of Positive Psychology, 5(4), 516-520. Retrieved from http://web.b.ebscohost.com.ric.idm.oclc.org/ehost/pdfviewer/pdfviewer?vid=12\& sid=e84e3de4-fd97-4517-bc82-c900ab55b72b\%40pdc-v-sessmgr02

Patnaik, G. (2014). Life skill enhancement strategies to minimize stress. Social Science International,30(2), 281-289. Retrieved from http://web.b.ebscohost.com.ric.idm.oclc.org/ehost/pdfviewer/pdfviewer?vid=7\&si d=fc66b040-9c88-4375-b92d-81df15ae73b4@sessionmgr101

Puri, P. (2019, January 31). The emotional toll of graduate school [Web log post]. Retrieved from https://blogs.scientificamerican.com/observations/the-emotionaltoll-of-graduate-school/ 
Sahu P. (2020). Closure of universities due to coronavirus disease 2019 (COVID-19): Impact on education and mental health of students and academic staff. Cureus, 12(4), e7541. https://doi.org/10.7759/cureus.7541

Sohail N. (2013). Stress and academic performance among medical students. Journal of the College of Physicians and Surgeons--Pakistan: JCPSP, 23(1), 67-71.

Stephens, M. A., \& Wand, G. (2012). Stress and the HPA axis: role of glucocorticoids in alcohol dependence. Alcohol Research: Current Reviews, 34(4), 468-483.

Steptoe, A., \& Kivimäki, M. (2013). Stress and cardiovascular disease: an update on current knowledge. Annual Review of Public Health, 34, 337-354. https://doi.org/10.1146/annurev-publhealth-031912-114452

Stone, L. (2012, May). Stress in nurse anesthesia educators and students. Retrieved from https://www.aana.com/docs/default-source/wellness-aana.com-web-documents(all)/stress-in-nurse-anesthesia-educators-and-students.pdf?sfvrsn=b2264bb1_2

Taylor J. M. (2015). Psychometric analysis of the ten-item Perceived Stress Scale. Psychological Assessment, 27(1), 90-101. https://doi.org/10.1037/a0038100

Tunajek, S. (2006). Student Stress: A question of balance. Retrieved from https://www.aana.com/docs/default-source/wellness-aana.com-web-documents(all)/student-stress-a-question-of-balance.pdf?sfvrsn=b3264bb1_2 
Uranga, T. (2015, July). Occupational stress and the resilience to overcome. AANA NewsBulletin, 28-29. Retrieved from https://cms.aana.com/docs/defaultsource/wellness-aana.com-web-documents-(all)/occupational-stress-and-theresilience-to-overcome.pdf?sfvrsn=e2d4bb1_2

Welle, P. D., \& Graf, H. M. (2011). Effective lifestyle habits and coping strategies for stress tolerance among college students. American Journal of Health Education, 42(2), 96-105. Retrieved from https://files.eric.ed.gov/fulltext/EJ918451.pdf.

World Health Organization Coronavirus Disease (COVID-19) Dashboard. (2020, August 22). Retrieved August 22, 2020, from https://covid19.who.int/

Wright, E. L., McGuiness, T., Moneyham, L. D., Schumacher, J. E., Zwerling, A., \& Stullenbarger, N. N. (2012, April). Opioid abuse among nurse anesthetists and anesthesiologists. American Association of Nurse Anesthetists Journal, 80(2), 120128.

Yaribeygi, H., Panahi, Y., Sahraei, H., Johnston, T., \& Sahebkar, A. (2017). The impact of stress on body function: A review. EXCLI Journal, (16), 1057-1072. doi:10.17179/excli2017-480 


\section{Appendix A}

Stress in Nurse Anesthesia Survey created by Chipas and McKenna (2011)

\section{Demographics}

Dear AANA member or Associate member,

STRESS and its effects on practitioner/student wellness are threats that can have undesirable outcomes in both our personal and professional lives. All of us have the ability to adapt to everyday pressures to a point, after which we experience stress that may manifest itself in many ways including changes in our health.

In 2008, the AANA conducted their first assessment of practitioner stress and wellness. This survey provided a baseline from which to work. As a component of the Wellness Program, the AANA Wellness Committee would like to again assess stress levels and the overall wellness of the AANA membership. This survey is being performed through SurveyMonkey an electronic instrument that will administer and analyze the data. We do not have the ability to track data on individuals. Data will be analyzed in the aggregate, therefore, your responses will not be individually identifable. Participation in this survey is strictly voluntary.

Findings from this survey will be used to target wellness initiatives specific to our members. Please help us by completing this survey which will take approximately 15 minutes. Your responses are confidential and important to help us implement initiatives to make life better for CRNAs and students. This survey has been approved by the Institutional Review Board for Human Research of the Medical University of South Carolina.

Thank you

Terry Wicks CRNA

Chairperson Wellness Committee

Tony Chipas CRNA, PhD

Professor/Director

Division of Anesthesia for Nurses

Medical University of South Carolina

\section{Did you participate in the stress and wellness survey in 2008?}

Yes

No

Cant remember

\section{If you took the survey in 2008 , what was your certification status?}

NA

Student

CRNA/Graduate nurse anesthetist

Not currently recertified

3. If you took the survey in 2008 , has your overall stress level changed?

Decreased

Increased

No change 
4. Has your health changed in the last year?

Yes, for the better

Yes, for the worse

No. remained unchanged

If yes, how? 


\section{Demographics}

5. Which one of the following most accurately describes your primary professional role? (Select one)

Partner/Owner anesthesia group

Hospital/Department Administrator

Chief CRNA

Staff CRNA

Program/Assistant Program Director

Educator

Locums

Student/Resident

\section{What is your primary practice setting?}

Student/Resident

- Anesthesia care team

Clinic/Acs

Hospital employee

Military

specialty group - nurse anesthetists only

solo Practice

Educator

Other

If Other (please specify)

7. If you work with students (in education), what is your primary role?

Administrator

clinical Instructor/Preceptor

Didactic Instructor

$\bigcirc_{N / A}$

8. In which state do you work?

State: 
9. How long have you been in this practice setting?

< 1 year

1 year

2 years

3 years

4-6 years

6- 10 years

> 10 years

10. How many hours do you work per week?

$0<20$

$20-25$

26.30

31.35

36.40

(11.45

46-50

O $>50$

11. Gender

Female

Male

12. What is your age group?

O $<25$

25-29

30.34

35.39

(0.44

(5. 49

50.54

55.59

60.64

(65+ 


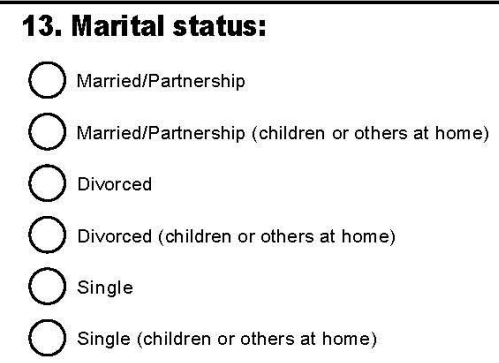

\section{Race/Ethnicity}

American Indian or Alaska Native

Asian

Black or African American

Hispanic

Native Hawaiian or other Pacific Islander

White (Non-Hispanic)

15. How many years have you been working in anesthesia?

$0<1$ year

1-5 years

6- 10 years

11- 15 years

$16 \cdot 20$ years

$21-25$ years

> $>25$ years

16. What is your BMI?

$0<25$

26.29

30.40

○1.55

O>55 
17. When was your last vacation?

$0-3$ months ago

4-6 months ago

7-11 months ago

$1-2$ years ago

$>2$ years ago

18. When was your last sick day?

0.3 months ago

4-6 months ago

7-11 months ago

$1-2$ years ago

$>2$ years ago

19. On average, how many sick days do you use per year?

O-2

3-5

6-8

○-10

O $>10$ 


\section{STUDENT INFORMATION ONLY}

This sections is for STUDENTS ONLY. If your are CRNA, please skip to the next section

20. PLEASE ANSWER ONLY IF YOU ARE A STUDENT. what type of program are you in?

Front loaded

Integrated

Not a student

21. How long is your program (in semesters)? PLEASE ANSWER ONLY IF YOU ARE A STUDENT
$\mathrm{O}_{5}$
$\mathrm{O}^{6}$
${ }_{7}$
$\mathrm{O}_{8}$
$\mathrm{O}_{9}$
$\bigcirc_{10}$
$\bigcirc_{11}$

22. What semester are you currently enrolled in? PLEASE ANSWER ONLY IF YOU ARE A STUDENT
1st
2nd
3rd
$\mathrm{O}_{4 \mathrm{th}}$
5th
$\mathrm{O}_{\text {th }}$
${ }^{7 t h}$
$\mathrm{O}_{\text {8th }}$
$\bigcirc_{9 \text { th }}$
10th $^{\text {th }}$
11th $^{1}$ 
23. PLEASE ANSWER ONLY IF YOU ARE A STUDENT. If you are in a front-loaded program, are you primarily in?

Didactic

Clinical

combined

Not front loaded

24. If you have reached the clinical phase of your program, where did you find the most stress? PLEASE ANSWER ONLY IF YOU ARE A STUDENT

Didactic

Clinical

Both equal

Not yet in clinical phase

25. How many hours of substance abuse education do you receive in your nurse anesthesia program? PLEASE ANSWER ONLY IF YOU ARE A STUDENT

O-1 hours

2-3hours

4-5hours

6.7hours

> 7 hours 


\section{Stress Symptoms}

26. Stress can be manifested in many ways. Some are more obvious than others. Please mark the frequency that each condition or feeling occurs to you during the last year. Weekly . . . . . . Occurs at least once every week

Monthly . . . . . . Occurs at least once per month but not every week Intermittent . . 3 or more times per year

N/A . . . . . . . . Not at all

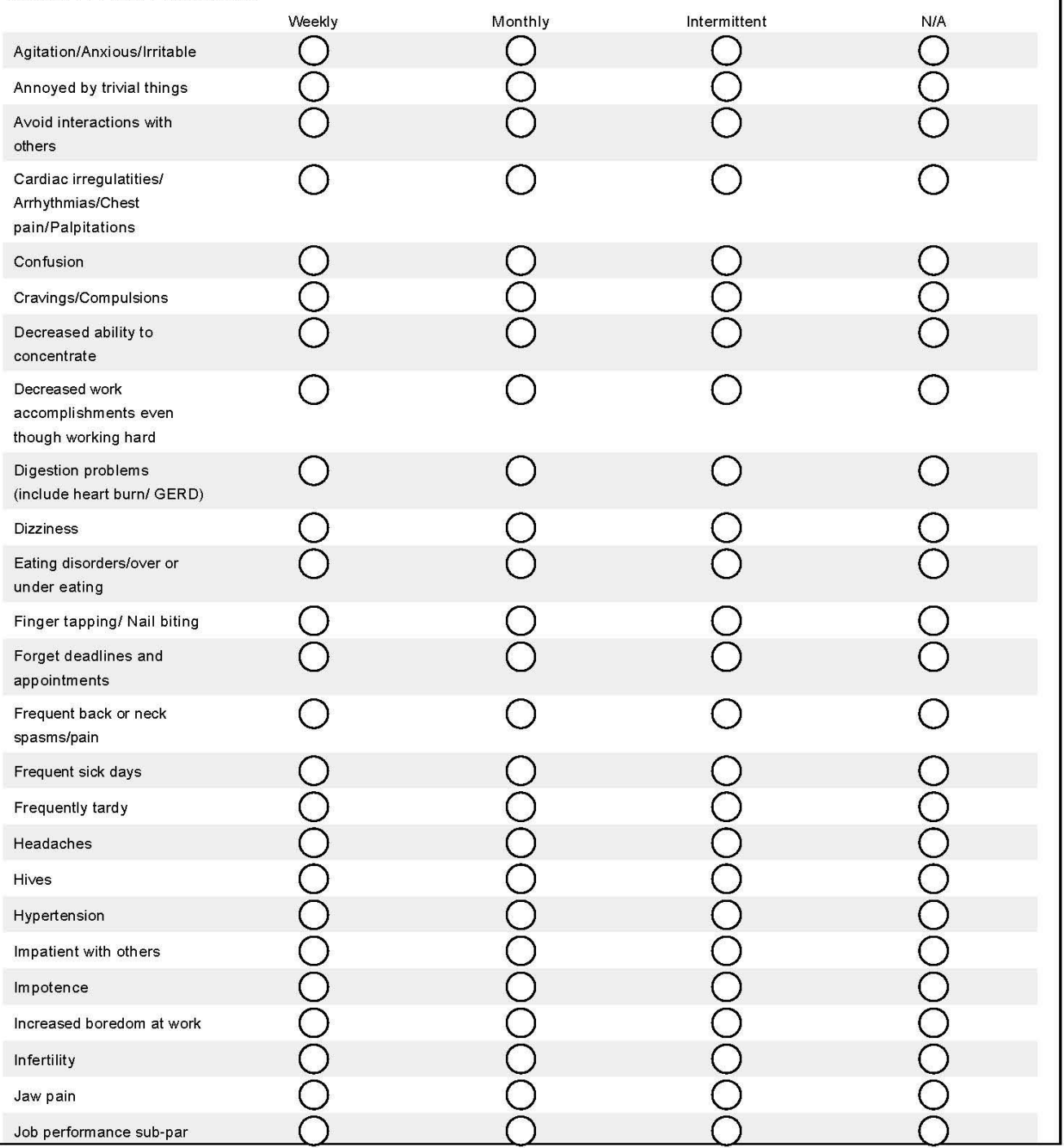




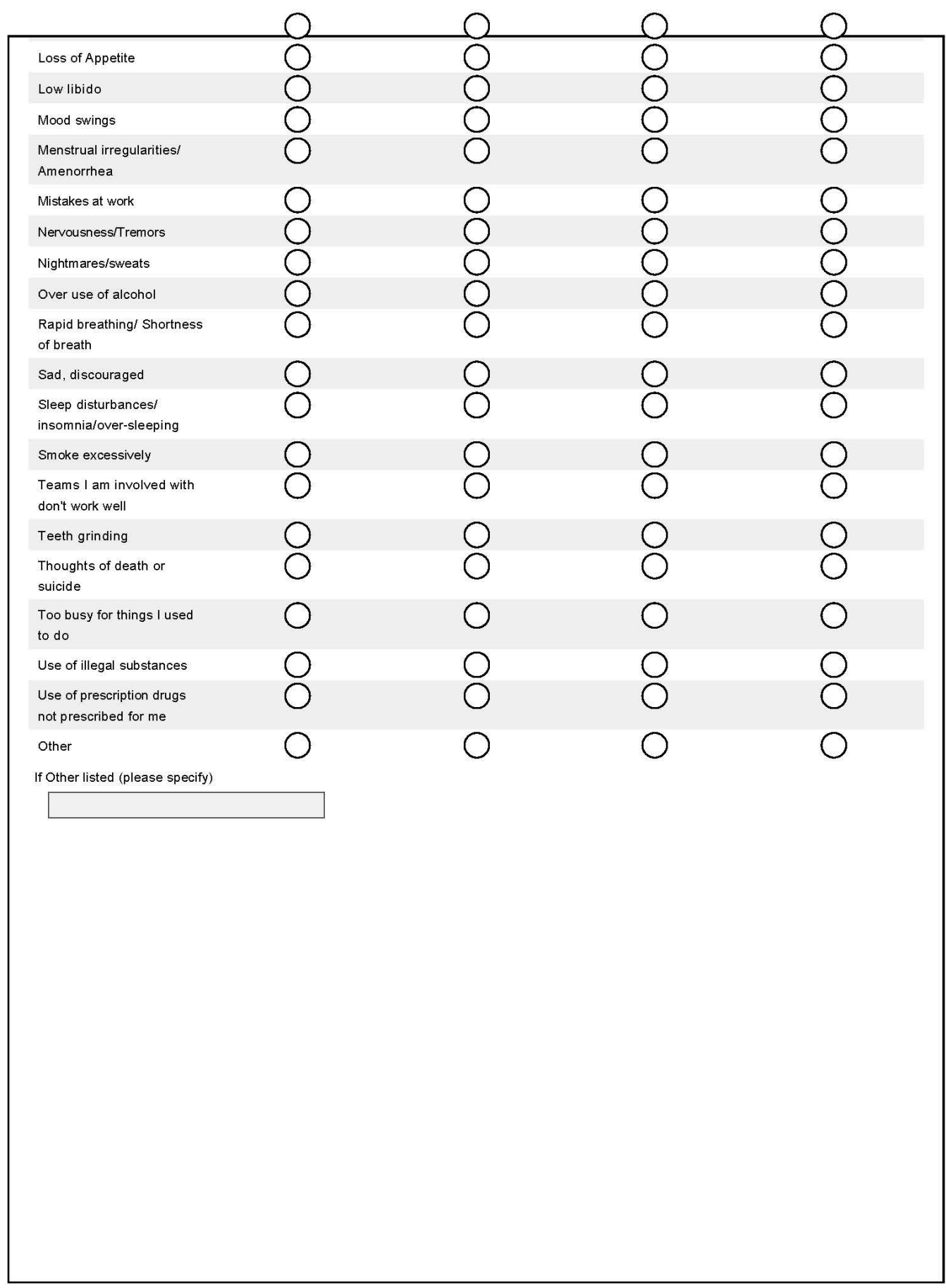


27. During the last year, have you had any of the following occur (please mark all that apply)?

\begin{tabular}{|c|c|}
\hline Salary/benefits decreased & Medical malpractice lawsuit \\
\hline Bankruptcy/ financial crisis & Military deployment - self \\
\hline Birth of a child & Military deployment - significant other/friend \\
\hline Caring for debilitated/chronically ill loved one & Moved \\
\hline Change jobs & Personal illness or injury \\
\hline Death of a spouse/partner/child & Pregnancy \\
\hline Death of a family member/close friend & Promation \\
\hline Dem otion & Quit a job \\
\hline Divorce & Regulatory audit (COA/JCAHO) \\
\hline Marital/Partner reconciliation & Retirement \\
\hline Marital/Partner separation & Started school \\
\hline
\end{tabular}

28. How would you rate your stress level on an average day?

1 Low stress

$\mathrm{O}_{2}$

$\mathrm{O}_{3}$

$\mathrm{O}_{4}$

5 Average stress

06

${ }_{7}$

O 8

O

10 Extreme stress 
29. How much of your stress is from your job or school?

${ }_{100 \%}$

${ }_{90 \%}$

$80 \%$

${ }_{70 \%}$

○ $60 \%$

○ $50 \%$

○ $40 \%$

$30 \%$

○20\%

○ $10 \%$

O

30. How satisfied are you with your job (place of employment)?

Extremely satisfied

Satisfied

Neutral

Dissatisfied

Extremely dissatisfied

31. Do you feel empowered to make changes at your place of employment/school? Yes

No

Comments:

32. How satisfied are you with your career in anesthesia?
Extremely satisfied
satisfied
Neutral
Dissatisfied
Extremely dissatisfied 
33. How satisfied are you with your life outside of work?

$\bigcirc$ Extremely satisfied

Satisfied

Neutral

Dissatisfied

Extremely dissatisfied

34. Do you feel empowered to make changes at your personal life?

Yes

No

Comments: 


\section{How you handle stress.}

35. These items deal with ways you've been coping with the stresses in your life. Each item says something about a particular way of coping. We want to know to what extent you have been doing what the item says. How much or how frequently, not whether it seems to be working.

I've been:

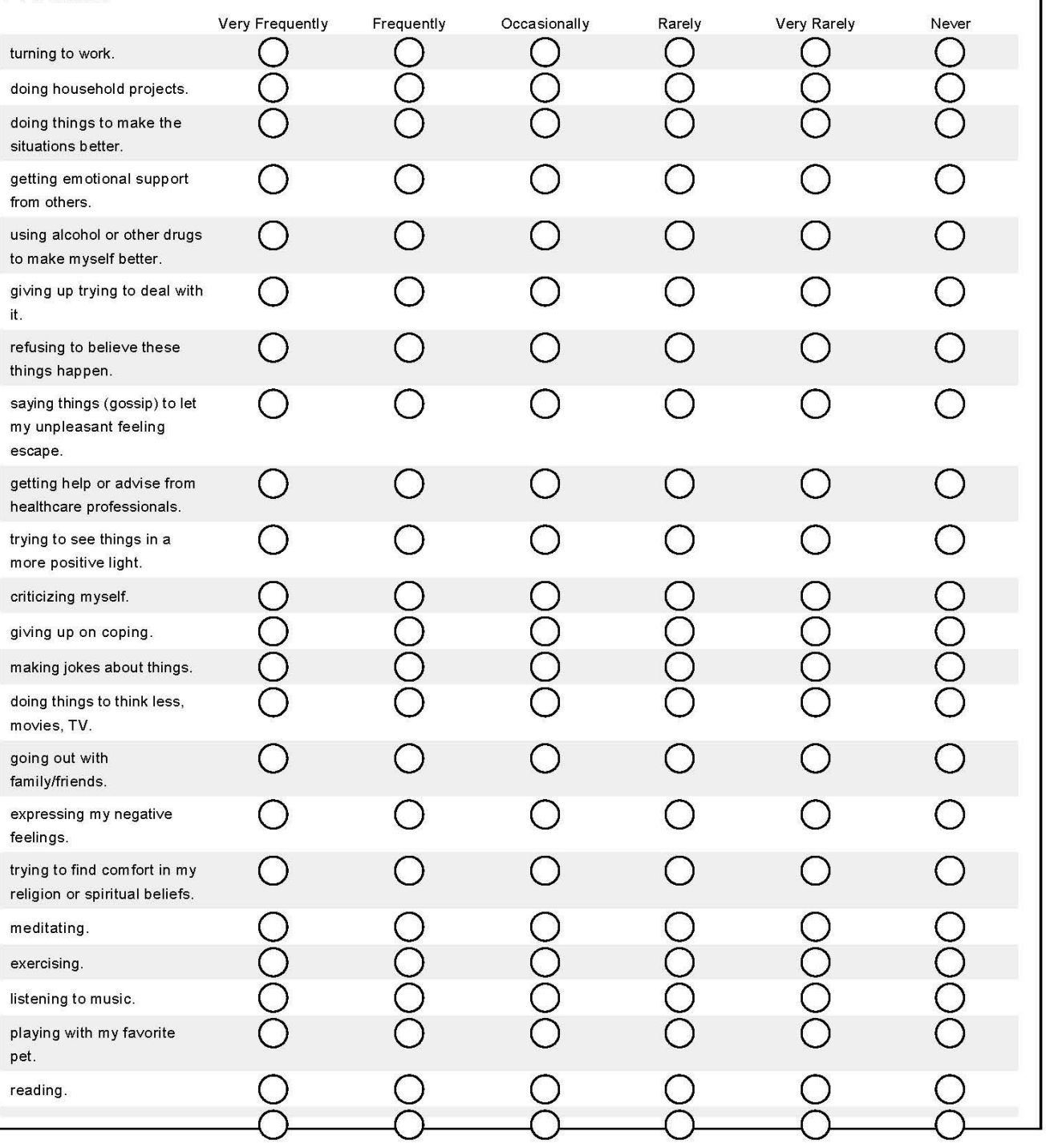




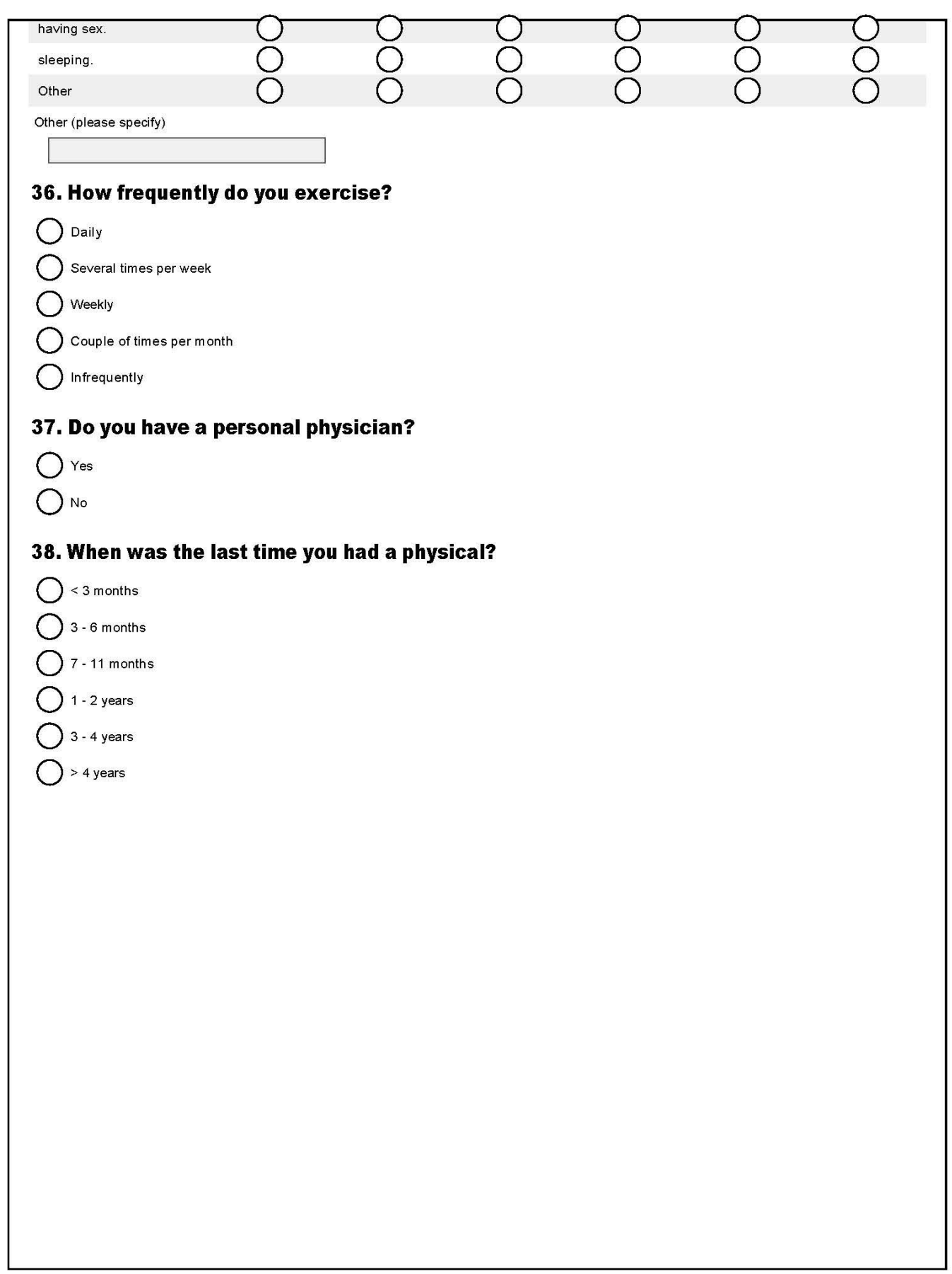


39. Do you suffer from any of the following chronic illnesses? (Mark all that apply to you)

\begin{tabular}{l}
$\square$ Carpal tunnel s, \\
$\square$ Chronic pain (in \\
$\square$ Depression \\
$\square$ Diabetes \\
$\square$ Fibromyalgia \\
$\square$ GERD (Digestiv \\
$\square$ Heart Disease \\
$\square$ Hypertension \\
$\square$ Latex allergy \\
$\square$ Other \\
$\square$ If other (please \\
\hline \\
40. When was \\
< 3 months \\
3 - 6 months \\
7 - 11 months \\
1 - 2 years \\
3 - 4 years \\
> 4 years
\end{tabular}

41. Are you now in recovery from chemical dependency(drug/ETOH addiction)?

Yes

No

42. Do you have a family history of chemical dependency (drug/ETOH addiction)?

Y Yes

№

43. During the last month, have you often been bothered by feeling down, depressed, or hopeless?

Yes

№ 
44. During the last two months, have you often been bothered by little interest or pleasure in doing things?

Yes

No

45. Have you ever thought of committing suicide?

Yes

No

46. Do you know of a CRNA/SRNA who has committed suicide in the last 2 years?

Yes

No

If yes, how?

47. Have you ever sought professional help for stress?

Yes

No

48. Are you currently (within the last 6 months) being treated for stress or a stress related problem?

Yes

No

49. Do you now or have you ever used prescription drugs to help handle stress?

Yes

No

If yes (please specify)

감 
50. Do you take any of the following classes of medications to help you manage stress or sleep? (Mark all that apply)

$\square$ Alcohol

$\square$ Antidepressants

$\square$ Antihypertensives

$\square$ Barbiturates

$\square$ Benzodiazepines

$\square$ Beta blockers

$\square$ H2 blockers

$\square$ MAOIs

$\square$ Over the counter sleep aids

$\square$ opioids

$\square$ Prescription sleep aids

Proton pump inhibitors

SSRIs

Other (please specify)

51. Do you have a wellness program at your place of work?

Yes

No

Unsure

52. Are you aware of the AANA Wellness Program?

Yes

No

53. Have you used any resources from the AANA Wellness Program?

Yes

No

If yes, what were they and do you feel these helped?

54. Are there ways a wellness program can help you?

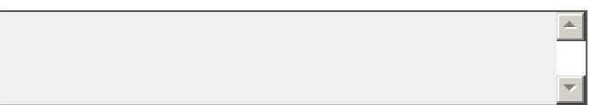




\section{Thank you}

Thank you for your participation. The AANA is here to serve and help protect our members.

Here are 10 ways to decrease stress.

1. Talk it out

2. Exercise

3. Avoid false guilt

4. Set realistic goals and priorities

5. Avoid perfectionism

6. Maintain a sense of humor

7. Hang loose. Set aside time to relax

8. Live by the calendar, not the stopwatch

9. Avoid overindulging in drugs, alcohol, caffeine and nicotine or food.

10. Think positive

Thank you for your help and support

Terry and Tony 


\section{Appendix B}

\section{Modified Survey}

\section{Demographics}

\section{Marital Status}

Married/partnership

Married/partnership (with children or others at home)

Divorced

Divorced (with children or others at home)

Single

Single (with children or others at home)

2. When was your last vacation?

0-3 months

4-6 months

7-11 months

1-2 years

$>2$ years

3. When was your last sick day?
0-3 months
4-6 months
7-11 months
1-2 years
$>2$ years $\bigcirc$

4. On average, how many sick days do you use per year?

$0-2$

3-5

$6-8$

9-10

$>10$ 


\section{Expected graduation date:}

December 2020

December 2021

\section{Stress Symptoms}

5. Stress can be manifested in many ways. Some are more obvious than others. Please mark the frequency that each condition or feeling occurs to you during the last year. Weekly ..... Occurs at least once every week. Monthly ..... Occurs at least once per month but not every week. Intermittent ...3 or more times per year. .......or Not at all

Agitation/Anxious/Irritable

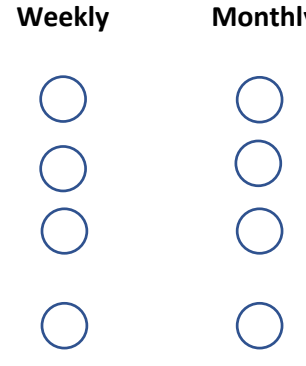

Intermittent Not at all

Annoyed by trivial things

Avoid interactions with others

Cardiac irregularities/

Arrhythmias/Chest pain/

Palpitations

Confusion

Cravings/Compulsions

Decreased ability to concentrate

Decreased work accomplishments

even though working hard
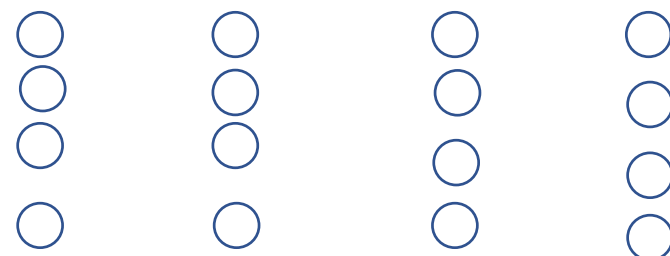

Digestion problems

(include heart burn/ GERD)

Dizziness

Eating disorders/over or

$$
\text { under eating }
$$

Finger tapping/ Nail biting

Forget deadlines and appointments

Frequent back or neck spasms/pain

Frequent sick days

Frequently tardy
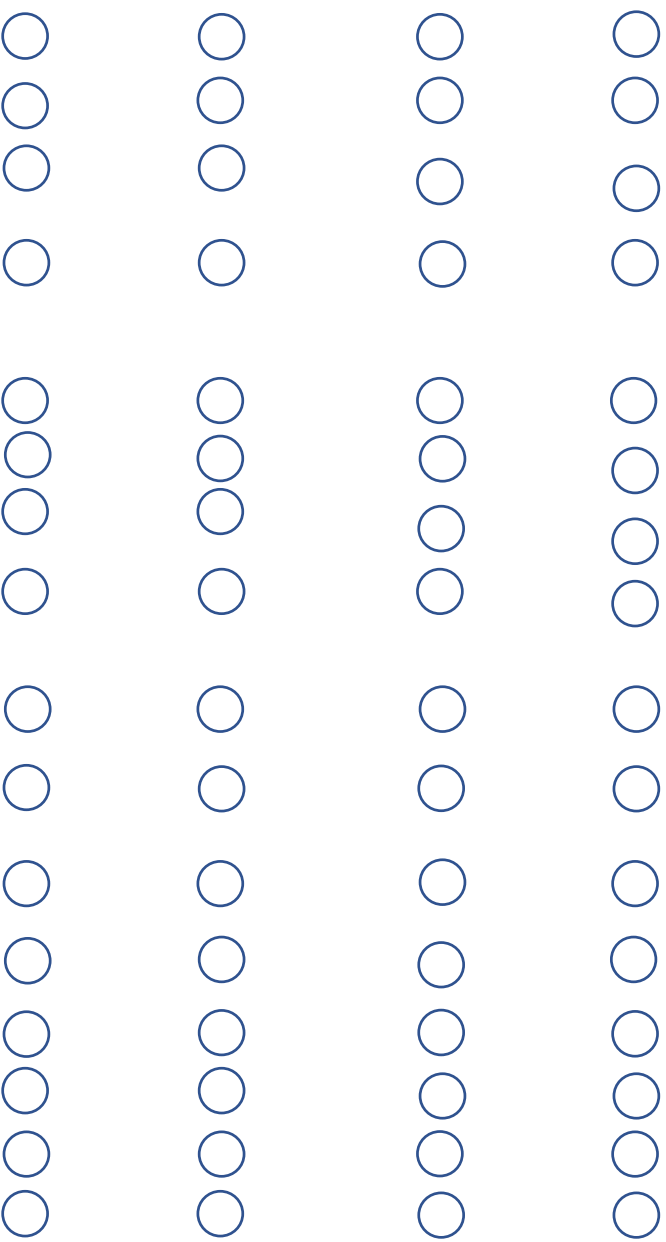

0 
Weekly

0

Impatient with others

Impotence

Increased boredom at work

Infertility

Jaw pain

Job performance subpar

Loss of Appetite

Low libido

Mood swings

Menstrual irregularities/ Amenorrhea

Mistakes at work

Nervousness/Tremors

Nightmares/sweats

Overuse of alcohol

Rapid breathing/ Shortness of breath

Sad, discouraged

Sleep disturbances/insomnia/oversleeping

Smoke excessively

Teams I am involved with don't work well

Teeth grinding

Thoughts of death or suicide

Too busy for things I used to do

Use of illegal substances

Use of prescription drugs not prescribed for me Other (Please specify below)
Monthly

Intermittent Not at all

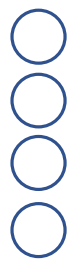

0

0

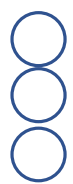

0
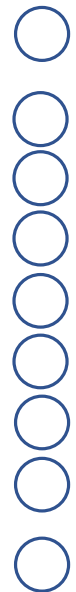

0

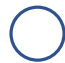

0

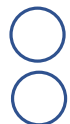

0

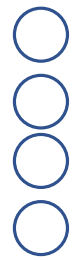

$\bigcirc$

$\bigcirc$

$\bigcirc$

$\bigcirc$

$\bigcirc$

0

$\bigcirc$

0

0

$\bigcirc$

0

$\bigcirc$

0

0

0

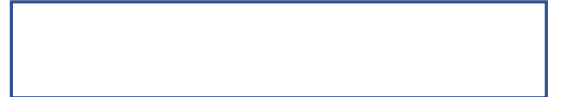


6. During the last year, have you had any of the following occur (please mark all that apply)?

Salary/benefits decreased

Birth of a child

Death of a spouse/partner/child

Divorce

Marital/Partner separation

Medical malpractice lawsuit

Military deployment significant other/friend

Personal illness or injury

Quit a job

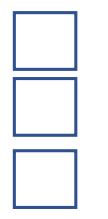

Bankruptcy/ financial crisis

Caring for debilitated/chronically ill loved one

Death of a family member/close friend

Marital/Partner reconciliation

Marriage/Legal union

Military deployment -self

Moved

Pregnancy
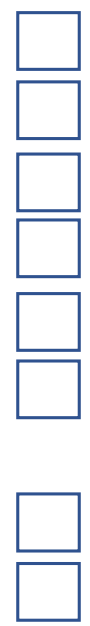

7. How would you rate your stress level on an average day?

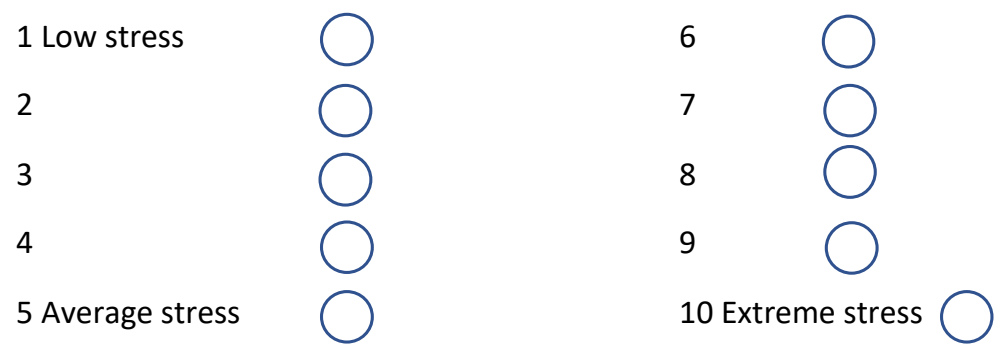

8. How much of your stress is from school?

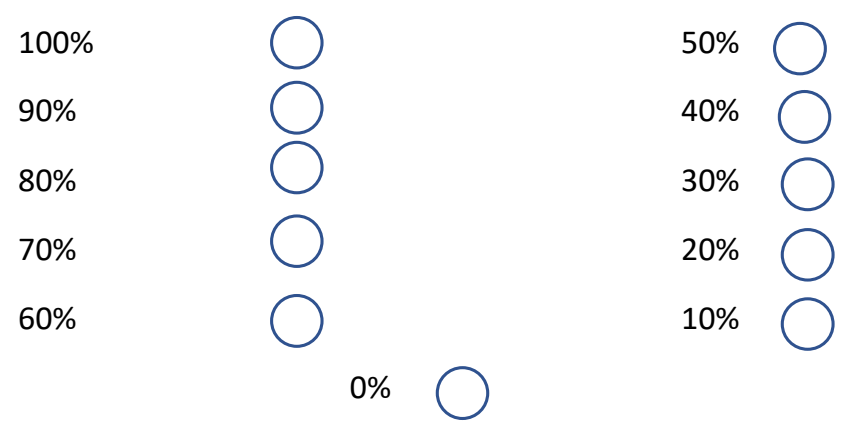


9. Do you feel empowered to make changes at your school?

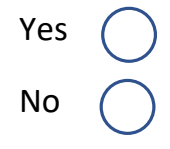

Comments:

10. How satisfied are you with your career in anesthesia?

Extremely satisfied

Satisfied

Neutral

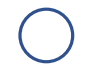

Dissatisfied

Extremely dissatisfied

11. How satisfied are you with your life outside of work?

Extremely satisfied

Satisfied

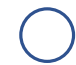

Neutral

Dissatisfied

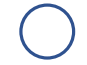

Extremely dissatisfied

12. Do you feel empowered to make changes at your personal life?

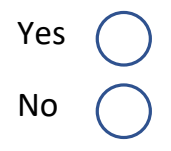

Comments: 


\section{How You Handle Stress}

13. These items deal with ways you've been coping with the stresses in your life. Each item says something about a particular way of coping. We want to know to what extent you have been doing what the item says. How much or how frequently, not whether it seems to be working.

I've been:

Very Frequently Frequently Occasionally Rarely Very Rarely Never

turning to work.

doing household projects.

doing things to make

the situations better.

getting emotional support from others.

using alcohol or other

drugs to make myself better.

giving up trying to deal with it.

refusing to believe these things happen.

saying things (gossip) to let

my unpleasant feeling escape.

getting help or advise from

healthcare professionals.

trying to see things in a more positive light.
0

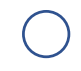

$\bigcirc$

$\bigcirc$

$\bigcirc$

$\bigcirc$

0

0

0

0 $\bigcirc$

0

0

0

0

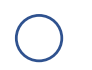

0

0

0

0

0

0

0

0

0

0

0

$O$

0

0

0

0

0

0

0

0

0<smiles>c1ccccc1</smiles>

$\bigcirc$

$\bigcirc$

$\bigcirc$

$\bigcirc$<smiles>c1ccccc1</smiles>

00000 


\begin{tabular}{|c|c|c|c|c|c|c|}
\hline & Very Frequently & Frequently & Occasionally & & Very Rarely & \\
\hline \multicolumn{7}{|c|}{ criticizing myself. } \\
\hline \multicolumn{7}{|c|}{ giving up on coping. } \\
\hline \multicolumn{7}{|c|}{ making jokes about things. } \\
\hline \multicolumn{7}{|c|}{ doing things to think less, movies, TV. } \\
\hline \multicolumn{7}{|c|}{ going out with family/friends. } \\
\hline \multicolumn{7}{|c|}{ expressing my negative feelings. } \\
\hline \multicolumn{7}{|c|}{ trying to find comfort in my } \\
\hline \multicolumn{7}{|c|}{ religion or spiritual beliefs. } \\
\hline \multicolumn{7}{|l|}{ meditating. } \\
\hline \multicolumn{7}{|l|}{ exercising. } \\
\hline \multicolumn{7}{|c|}{ listening to music. } \\
\hline \multicolumn{7}{|c|}{ playing with my favorite pet. } \\
\hline \multicolumn{7}{|l|}{ reading. } \\
\hline having sex. & & & & & & \\
\hline
\end{tabular}

Other (please specify): 
14. How frequently do you exercise?

Daily

Several times per week

Weekly $\bigcirc$

Couple of times per month

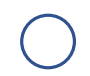

Infrequently

15. Do you have a personal physician?

Yes $\bigcirc$

No $\bigcirc$

16. When was the last time you had a physical?

$<3$ months

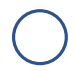

3-6 months

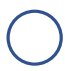

7-11 months

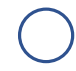

1-2 years

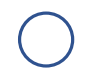

3-4 years

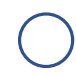

$>4$ years

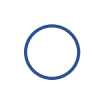


17. Do you suffer from any of the following chronic illnesses? (Mark all that apply to you)

Carpal tunnel syndrome

Depression

Fibromyalgia

Heart Disease

Latex allergy

Narcolepsy

Panic disorders

Seizure disorders

Substance misuse-illicit

Systemic Lupus
Chronic pain (including back and joint)

Diabetes

GERD (Digestive disorders)

Hypertension

Multiple Sclerosis

Obesity (BMI>25)

Rheumatoid arthritis

Stroke

Substance misuse-prescription

If other (please specify):

18. When was the last time you went to the dentist?

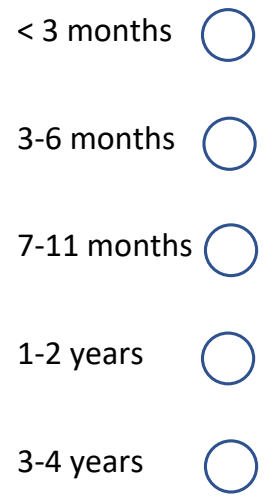


$>4$ years

19. Do you have a family history of chemical dependency (drug/ETOH addiction)?

Yes

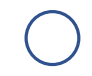

No

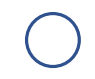

20. During the last month, have you often been bothered by feeling down, depressed, or hopeless?

Yes

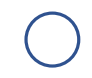

No

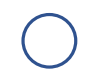

21. During the last two months, have you often been bothered by little interest or pleasure in doing things?

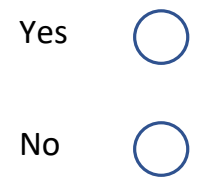

22. Have you ever thought of committing suicide?

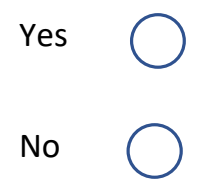

23. Do you know of a CRNA/SRNA who has committed suicide in the last 2 years?

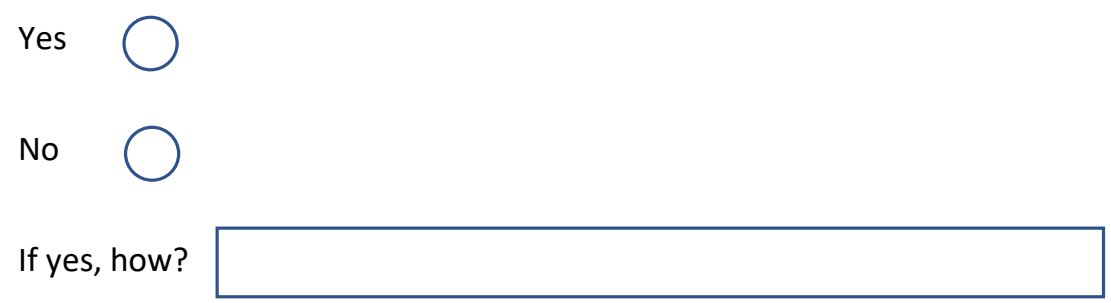


24. Have you ever sought professional help for stress?

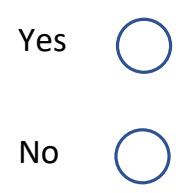

25. Are you currently (within the last 6 months) being treated for stress or a stress related problem?

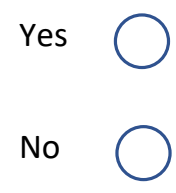

26. Do you now or have you ever used prescription drugs to help handle stress?

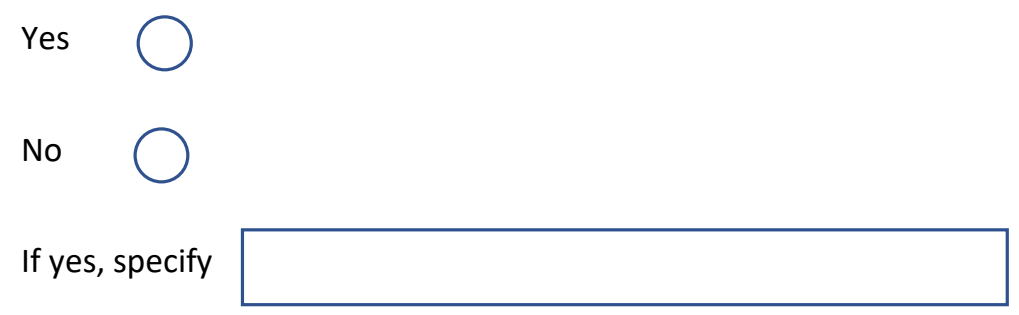

27. Do you take any of the following classes of medications to help you manage stress or sleep? (Mark all that apply)

Alcohol

Antihypertensives

Benzodiazepines

H2 blockers

Over the counter sleep aids

Prescription sleep aids

SSRIS
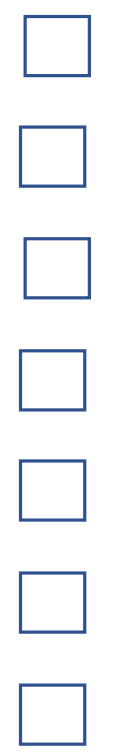

Antidepressants

Barbiturates

Beta blockers

MAOIs

Opioids

Proton pump inhibitors
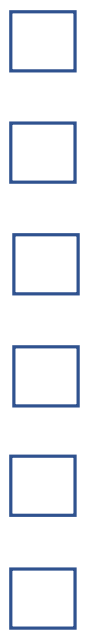


\section{2020 COVD-19 Pandemic}

28. How would you rate the degree of additional stress added from the global pandemic, COVID-19?

1 Low Stress

2

3

4

5 Average stress
6

7

8

$9 \bigcirc$

10 Extreme stress

29. How satisfied are you with how your program handled your education and well-being during this difficult time?

Extremely satisfied

Satisfied

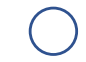

Neutral

Comments:

30. What contributed most to the additional stress?

Financial concerns

Health of self

Health of a loved one

Deferment of graduation

Other (please specify):
Dissatisfied

Extremely dissatisfied 